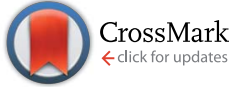

Cite this: J. Mater. Chem. A, 2016, 4, 6527

Received 14th February 2016

Accepted 6th April 2016

DOI: $10.1039 / c 6 t a 01355 d$

www.rsc.org/MaterialsA

\section{Synthesis, characterization and DFT studies of zinc- doped copper oxide nanocrystals for gas sensing applications $\uparrow$}

\begin{abstract}
V. Cretu, ${ }^{a}$ V. Postica, ${ }^{a}$ A. K. Mishra, ${ }^{\text {b }}$ M. Hoppe, ${ }^{c}$ I. Tiginyanu, ${ }^{a}$ Y. K. Mishra, ${ }^{c}$ L. Chow, ${ }^{d}$ Nora H. de Leeuw, ${ }^{\text {be }}$ R. Adelung ${ }^{c}$ and O. Lupan ${ }^{\star a c}$

Due to their unique properties, p-type copper oxide nanostructures have demonstrated promising potential for various applications, especially for the detection of ethanol vapour and other volatile organic compounds (VOCs). In this work a simple and cost-effective synthesis from chemical solutions (SCS) at low temperatures $\left(\leq 80^{\circ} \mathrm{C}\right)$ and rapid thermal annealing (RTA) process were used to grow zinc-doped copper oxide $\left(\mathrm{Zn}_{x} \mathrm{Cu}_{1-x} \mathrm{O}_{y}\right)$ nanostructures. The structural, morphological, vibrational, chemical, electronic and sensorial characteristics of $\mathrm{Zn}_{x} \mathrm{Cu}_{1-x} \mathrm{O}_{y}$ nanocrystallite layers obtained by using such an efficient approach based on both, the SCS and RTA processes, have been studied. The investigations demonstrated the possibility to tune sensitivity from VOC to $\mathrm{H}_{2}$, as well as an improved response and high selectivity with respect to hydrogen gas for $\mathrm{Zn}_{x} \mathrm{Cu}_{1-x} \mathrm{O}_{y}$ nano-crystalline thin films with $x=0.03$. Density functional theory calculations showed that the charge transfer together with changes in the Fermi level facilitate $\mathrm{H}_{2}$ gas sensing, which is further enhanced by $\mathrm{Zn}$ doping. Hydrogen gas sensing with a high response and selectivity using p-type hybrid semiconductor nanostructures has been reported. An improved stability in humid air was observed by exposure of doped samples to rapid thermal annealing process for the first time. The experimental and calculation results provide an alternative to sensitive and selective detection of ethanol and hydrogen gases, which would be of particular benefit in the area of public security, industrial and environmental applications.
\end{abstract}

\section{Introduction}

Hydrogen is widely used in industries, as a power source in aerospace, for metal sintering and annealing, in research laboratories, biomedical systems, automotive and transportation equipment, etc. ${ }^{\mathbf{1 - 8}}$ Therefore, the reliable, selective and fast detection of hydrogen gas leaks appears to be the strict necessity for preventing the accumulation of hydrogen in air $\left(4 \% \mathrm{H}_{2}\right) .{ }^{6}$ In this context nano- and microstructures of p-type materials and especially the n-type semiconducting oxides have been intensively investigated over the past few decades due to

${ }^{a}$ Department of Microelectronics and Biomedical Engineering, Technical University of Moldova, 168 Stefan cel Mare Av., MD-2004 Chisinau, Republic of Moldova

${ }^{b}$ Department of Chemistry, University College London, 20 Gordon Street, London WC1H OAJ, UK. E-mail: n.h.deleeuw@ucl.ac.uk; deleeuwn@cardiff.ac.uk; abhishek. mishra@ucl.ac.uk

${ }^{c}$ Faculty of Engineering, Institute for Materials Science, Christian-Albrechts Universität zu Kiel, Kaiserstr. 2, D-24143, Kiel, Germany. E-mail: ra@tf.uni-kiel.de; ollu@tf.uni-kiel.de; lupanoleg@yahoo.com

${ }^{d}$ Department of Physics, University of Central Florida, Orlando, FL 32816-2385, USA ${ }^{e}$ School of Chemistry, Cardiff University, Main Building, Park Place, Cardiff CF10 3AT, $U K$

$\dagger$ Electronic supplementary information (ESI) available. See DOI: 10.1039/c6ta01355d their remarkable gas sensing properties, and importance for fundamental research and applied technologies. ${ }^{9-12}$ Due to their unique properties and specific gas sensing mechanism, $\mathrm{p}$-type copper oxide nanostructures have demonstrated promising potentials in various gas sensing applications, especially in detection of ethanol vapour and other volatile organic compounds (VOCs), like benzene, acetone and toluene, etc. ${ }^{\mathbf{1 3 - 1 7}}$ Copper oxide semiconductors and their derivatives are excellent candidates for the fabrication of low-cost p-type nanosensors due to high abundance of copper in nature, ${ }^{18}$ simple synthesis and nanointegration methods. ${ }^{19}$

However, most of the reported studies on gas sensing properties of copper oxides with different types of morphologies have demonstrated selective ethanol or acetone vapour sensing ${ }^{\mathbf{1 4 2 0 , 2 1}}$ and only a few reports reveal the selectivity and response with respect to hydrogen gas. ${ }^{17,22-24}$ In this context, the change of chemical and physical properties by doping of foreign elements is an important and efficient way to further control the gas sensing characteristics of semiconducting oxides such as sensitivity, response and recovery times, as well as selectivity. ${ }^{\mathbf{1 6}}$ From the existing literature, it is difficult to find any study which demonstrates the p-type nanomaterials based hydrogen gas sensing with high response/selectivity characteristics. 
In this work, the synthesis of zinc-doped copper oxides, $\mathrm{Zn}_{x} \mathrm{Cu}_{1-x} \mathrm{O}_{y}$, nano-crystalline films by a synthesis from chemical solutions (SCS) method and rapid thermal annealing (RTA) process has been developed. We report on the details of the growth process, phase analysis, chemical composition, vibrational and sensorial performances of the functional copper oxide treated by conventional thermal annealing (TA) in electrical furnace and by RTA in air. A mixed phase of CuO:Zn/ $\mathrm{Cu}_{2} \mathrm{O}: \mathrm{Zn}$ in samples TA-treated at $400-450{ }^{\circ} \mathrm{C}$ for $30 \mathrm{~min}$ and RTA-treated at $525{ }^{\circ} \mathrm{C}$ for $60 \mathrm{~s}$ was detected by XRD, EDX and micro-Raman measurements. An enhanced $\mathrm{H}_{2}$ gas response and improved stability to humidity of RTA-treated samples with high $\mathrm{Zn}$ content was demonstrated by gas sensing measurements. Based on the ionosorption model and density functional theory (DFT) calculations, the gas sensing mechanism was proposed.

\section{Experimental}

Pure copper oxides, $\mathrm{Cu}_{x} \mathrm{O}_{y}$, and zinc-doped copper oxides, $\mathrm{Zn}_{x^{-}}$ $\mathrm{Cu}_{1-x} \mathrm{O}_{y}$, nano-crystalline films were grown on glass substrates (microscope slides $76 \mathrm{~mm} \times 25 \mathrm{~mm} \times 1 \mathrm{~mm}$ ) via SCS. The procedure of substrate cleaning was described in our previous work. ${ }^{25}$ The substrate surface was sensitized with $\mathrm{SnCl}_{2} / \mathrm{HCl}$ solution. ${ }^{26,27}$ For SCS deposition process the substrates were immersed vertically in the solutions using a microcontroller based system to grow $\mathrm{Cu}_{2} \mathrm{O}$ nanostructured films with desired thickness, by controlling the number of cycles and time of substrate immersion in the solutions. The deposition system includes a home-made robot arm, controlled by a microcontroller through a graphical user interface (GUI), with the possibility to send commands and set parameters through a wireless module. A typical schematic for our set-up with related description is represented in Fig. S1. $\dagger$ The main advantage of the presented system is the exclusion of errors due to human factors which actually leads to high reproducibility of the samples and commodity in synthesis process. Wireless communication allows operation control out of fume hood in case of work with toxic chemicals or in the case of emanation of harmful gases after chemical reactions in the deposition process.

The aqueous copper-complex solution, as cation precursor, comprises a mixture of $1 \mathrm{M}$ copper sulfate $\left(\mathrm{CuSO}_{4} \cdot 5 \mathrm{H}_{2} \mathrm{O}\right)$ and $1 \mathrm{M}$ sodium thiosulfate $\left(\mathrm{Na}_{2} \mathrm{~S}_{2} \mathrm{O}_{3} \cdot 5 \mathrm{H}_{2} \mathrm{O}\right)$. In order to prepare the Zn-doped nano-crystalline films, two new baths, one containing $\mathrm{Cu}^{+}$ions and the other filled with only deionized (DI) water, were included in the growth system. The $\mathrm{Zn}$ doping of $\mathrm{Cu}_{2} \mathrm{O}$ nanostructured films was achieved by adding $\mathrm{ZnSO}_{4} \cdot 7 \mathrm{H}_{2} \mathrm{O}$ in the copper complex solution corresponding to the necessary concentration of $\mathrm{Zn}$ in nanostructured films. For doping concentrations (\#1) - $1.5 \mathrm{mM},(\# 2)-4 \mathrm{mM}$ and (\#3) - $6 \mathrm{mM}$ of zinc ions were added in complex solutions, thus the $\mathrm{Zn}$ doping level from 0 to $3 \mathrm{wt} \% \mathrm{Zn}$ was varied according to EDX results. Deionized water (resistivity $18.2 \mathrm{M} \Omega \mathrm{cm}$ ) was used as solvent. $\mathrm{NH}_{4} \mathrm{OH}$ was added to the initial solution to control the complex solution and the value of $\mathrm{pH}$ was 10 . The copper complex solution was diluted with DI water to obtain $0.1 \mathrm{M}$ copper concentration and was maintained at room temperature during the film deposition. The anionic precursor solution comprises sodium hydroxide $(\mathrm{NaOH})$ diluted with DI water to obtain $2 \mathrm{M}$ and was maintained at $80{ }^{\circ} \mathrm{C}$ during the film deposition. All chemicals were of reagent grade. After deposition, the nanocrystalline films were rinsed well with DI water, and then dried for $5 \mathrm{~min}$ at $150{ }^{\circ} \mathrm{C}$ in air flux. The global reaction of copper complex solution preparation for $\mathrm{Cu}_{2} \mathrm{O}$ nano-crystalline films deposition was described in previous works. ${ }^{11,28}$ A single deposition cycle of a $\mathrm{Cu}_{2} \mathrm{O}$ nano-crystalline film is described by the following two steps: (1) immersion of substrate in the hot $\left(80{ }^{\circ} \mathrm{C}\right)$ alkali solution for the adsorption of the $(\mathrm{OH})^{-}$ions on the glass substrate; (2) dipping this substrate in the thiosulfatocuprate(I) for reaction of the copper ions and zinc ions with adsorbed $(\mathrm{OH})^{-}$. This is one cycle of the ion layers adsorption and reaction processes in our method. The copper ions are formed by the dissociation equilibrium. ${ }^{11,28}$

Equation of $\mathrm{Cu}_{2} \mathrm{O}$ forming is represented by: ${ }^{11,28}$

$$
2 \mathrm{Cu}^{+}+2 \mathrm{OH}^{-} \rightarrow 2 \mathrm{CuOH} \rightarrow \mathrm{Cu}_{2} \mathrm{O}+\mathrm{H}_{2} \mathrm{O}
$$

Post-growth treatment is an important factor to increase the crystallinity of nanostructured oxide films after chemical synthesis. ${ }^{\mathbf{1 1 , 2 8}}$ In this work, the as-grown films were subjected to two types of post-growth treatments in air, namely conventional thermal annealing (TA) in an electrical furnace and rapid thermal annealing (RTA). ${ }^{29}$ Typical schematic temperature profiles for TA and RTA - treatments at $450{ }^{\circ} \mathrm{C}$ and $525{ }^{\circ} \mathrm{C}$ are represented in Fig. $\mathrm{S} 2 \mathrm{a}$ and $\mathrm{b}, \dagger$ respectively. A typical schematic diagram of our RTA set-up is represented in Fig. S2c. $\dagger$

The samples morphology was investigated by using scanning electron microscopy (SEM) REM-ZEISS (at $7 \mathrm{kV}$ ). The chemical composition of the SCS samples was examined by EDX spectroscopy. Concentrations of $\mathrm{Zn}$ dopants in copper oxide layers were noted and found as (\#1 or c1) - $1.9 \mathrm{wt} \% \mathrm{Zn}$, (\#2 or c2) - 2.7 wt\% Zn; (\#3 or c3) - $3.0 \mathrm{wt} \% \mathrm{Zn}$ in the case of RTA treated samples and (\#1 or c1) - 1.9 wt\% Zn, (\#2 or c2) - $2.4 \mathrm{wt} \% \mathrm{Zn}$; (\#3 or c3) - $2.8 \mathrm{wt} \% \mathrm{Zn}$ in the case of TA treated specimens. Crystallographic data were obtained from X-ray powder diffraction (XRD) investigations using a Seifert XRD3000 PTS instrument operating at $40 \mathrm{kV}$ and $40 \mathrm{~mA}$, with $\mathrm{CuK} \alpha_{1}$ radiation, $\lambda=1.54184 \AA$ A. Secondary ion mass spectroscopy (SIMS) studies were performed with a Physical Electronics ADEPT 1010 quadrupole analyzer. The primary beam (25 nA) was applied to a $300 \mu \mathrm{m}$ by $300 \mu \mathrm{m}$ area, with the detection of negative secondary ions from an area of $100 \mu \mathrm{m}$ by $100 \mu \mathrm{m}$ at the centre. Technical information of the experiment can be found in our earlier reports. ${ }^{7,30,31}$ Micro-Raman studies were performed at room temperature with a WITec alpha 300 RA system in a backscattering configuration. The Nd-YAG laser power was less than $4 \mathrm{~mW}$ at the sample. ${ }^{7}$ The investigated sample sizes were $5 \mathrm{~mm}$ in width and few $\mathrm{cm}$ in length. Each measurement was performed on an individual sample and re-checked on several ones from the same set. Electrical studies were carried out using the two-point probe method at room temperature. Gas sensing properties were evaluated according to the previous reports. ${ }^{\mathbf{8}, 32,33}$

Different values of relative humidity $(\mathrm{RH})$ were generated using a bubbling system. Air was passed through water and 
then was continuously injected into the chamber to create the necessary RH value. The humidity was continuously monitored by a standard hygrometer. More details can be found in previous works..$^{8,32,33}$

\section{Computational methodology}

Density functional theory (DFT) calculations were realized by the Vienna $A b$ initio Simulation Package (VASP) with a planewave basis set. ${ }^{34-37}$ The projector augmented wave method was certified to describe the interaction between electrons and ions, ${ }^{38}$ and the non-local exchange correlation energy was considered using the Perdew-Burke-Ernzerhof functional. ${ }^{39,40}$ The Hubbard model was involved to treat strong correlations within the DFT $+U$ method in the Dudarev formalism. ${ }^{\mathbf{4 1}}$

Recently, we have determined a value of $U$ that can efficiently describe both copper I and II oxides ${ }^{42}$ and this effective $U$ value of $7 \mathrm{eV}$ was chosen for the localized $3 \mathrm{~d}$ electrons of $\mathrm{Cu}$, whereas $U=6 \mathrm{eV}$ was taken for the $\mathrm{Zn}-3 \mathrm{~d}$ electrons. ${ }^{\mathbf{4 3}}$ The atomic structures were relaxed using the tetrahedron method with Bloch correction as implemented in VASP and the positions of all atoms in the cell were fully relaxed until the atomic forces on each ion were less than $0.01 \mathrm{eV}^{-1}$. To model $\mathrm{Zn}$ doping, we have used our earlier bulk and surface models of $\mathrm{CuO}$ and $\mathrm{Cu}_{2} \mathrm{O}^{\mathbf{4 2 , 4 4}}$ We have further used the implementation of the DFT-D2 approach described by Grimme ${ }^{45}$ to account for long-range dispersion forces.

We sampled the $(1 \times 1)$ surface cells with a $5 \times 5 \times 1$ Monkhorst-Pack ${ }^{46} k$-point mesh, while $(2 \times 1)$ supercells were modelled with $2 \times 4 \times 1 k$-point mesh. Electronic density-ofstates $(D O S)$ of $(2 \times 1)$ supercells were calculated using a higher $4 \times 8 \times 1 k$-point mesh with a tetrahedron smearing parameter of $0.1 \mathrm{eV}$ and a Self-Consistent-Field (SCF) convergence criterion of $1 \times 10^{-6} \mathrm{eV}$ per unit cell.

The binding energy of $\mathrm{H}_{2}$ molecule was calculated from the relation:

$$
E_{\mathrm{ads}}=E_{\mathrm{CuO} / \mathrm{Cu}_{2} \mathrm{O}-\mathrm{Zn}+\mathrm{H}_{2}}-\left(E_{\mathrm{CuO} / \mathrm{Cu}_{2} \mathrm{O}-\mathrm{Zn}}+E_{\mathrm{H}_{2}}\right)
$$

where $E_{\mathrm{CuO} / \mathrm{Cu}_{2} \mathrm{O}-\mathrm{Zn}+\mathrm{H}_{2}}$ is the total energy of the $\mathrm{H}_{2}$ molecule adsorbed on the $\mathrm{Zn}$-doped $\mathrm{CuO}$ or $\mathrm{Cu}_{2} \mathrm{O}$ surface, $E_{\mathrm{CuO} / \mathrm{Cu}_{2} \mathrm{O}-\mathrm{Zn}}$ is the energy of the naked surface slab of $\mathrm{Zn}$-doped $\mathrm{CuO}$ or $\mathrm{Cu}_{2} \mathrm{O}$, and $E_{\mathrm{H}_{2}}$ is the energy of the isolated $\mathrm{H}_{2}$ molecule. Within this definition, negative adsorption energy indicates an exothermic process. While calculating, $E_{\mathrm{H}_{2}}$, we modelled the isolated $\mathrm{H}_{2}$ molecule in the centre of a broken symmetry cell with lattice constants of $20 \AA$, sampling only the gamma-point of the Brillouin zone with the same accuracy parameters as described for the surfaces. A Bader analysis was performed with the code developed by Henkelman and co-workers, ${ }^{47,48}$ to quantify the charge transfer between $\mathrm{H}_{2}$ molecule and the surfaces.

\section{Results and discussion}

\section{Morphological SEM and compositional EDX studies}

To investigate the surface morphology of SCS grown $\mathrm{Zn}_{x^{-}}$ $\mathrm{Cu}_{1-x} \mathrm{O}_{y}$ nano-crystalline films, SEM was used. The corresponding images are shown in Fig. 1 and S3. $\dagger$ In general, the nano-crystalline layers are homogeneously and continuously covering the glass substrates (see Fig. 1 and S3†).

Large islands layers are difficult to see in the sintered films formed from well-packed nanocrystallites of copper oxides covering completely the whole substrate. Typical SEM images of the as-grown films are presented in Fig. 1a-c for Zn-doped copper oxide layers with concentrations (\#1 or c1), (\#2 or c2) and (\#3 or c3), respectively. SEM of undoped $\mathrm{CuO}-\mathrm{Cu}_{2} \mathrm{O}$ can be found in our recent work. ${ }^{13}$ The film thickness was measured by cross-sectional SEM and the typical thickness was $\sim 1 \mu \mathrm{m}$. For samples after RTA at $725{ }^{\circ} \mathrm{C}$ (noted as RTA725 in Fig. 1g-i) or after TA at $650{ }^{\circ} \mathrm{C}$ (noted as TA650, see Fig. $1 \mathrm{~m}-\mathrm{O}$ and S3 and $\mathrm{S} 4 \dagger$ ), relatively large particle agglomerates can be observed in contrast to films treated at lower temperatures of RTA at $525{ }^{\circ} \mathrm{C}$ (RTA525, see Fig. 1d-f) or TA at $450{ }^{\circ} \mathrm{C}$ (TA450, see Fig. $1 \mathrm{j}-\mathrm{l}$ ). In these samples, marked as RTA525 and TA450, the films morphology appeared most uniform and the nanoparticle size was smaller (of about 40-60 nm). The films are formed from densely packed grains of approximately pyramidal form (Fig. 1d-f and j-l).

With further rise in sintering temperature up to $650{ }^{\circ} \mathrm{C}$ (for TA treated samples), and up to $725^{\circ} \mathrm{C}$ for RTA, it appears that

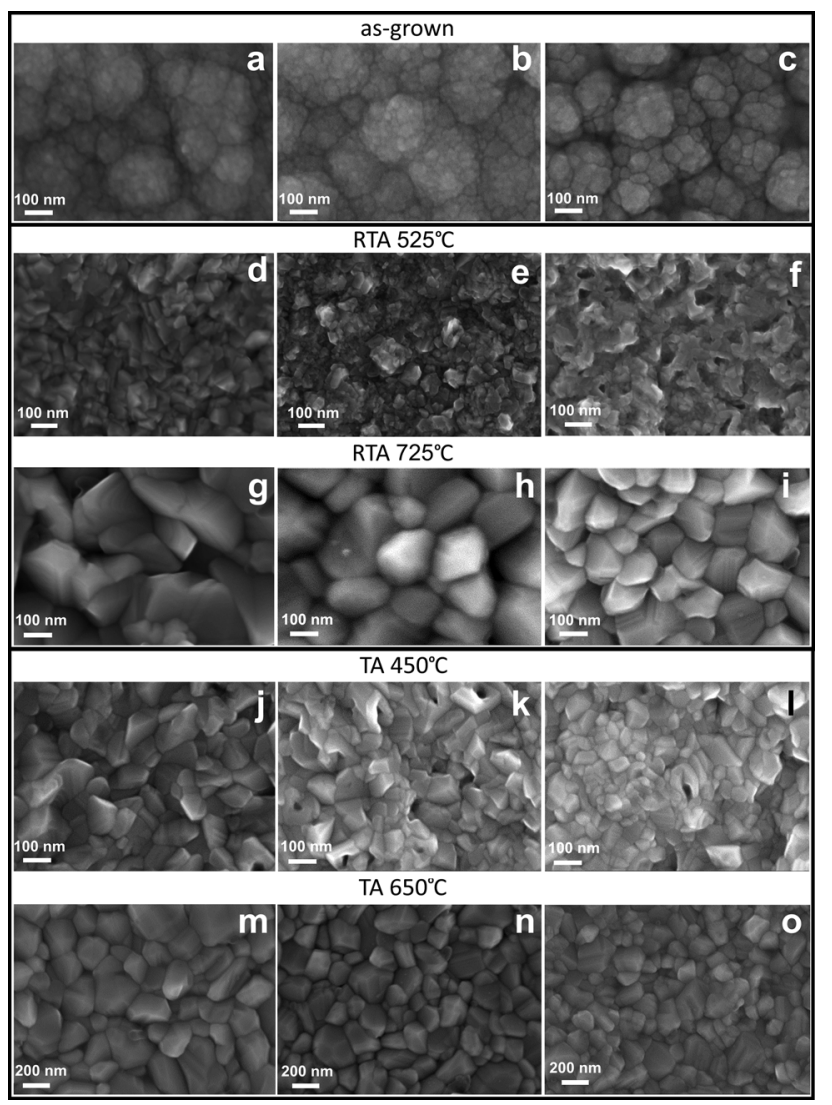

Fig. 1 SEM images of zinc-doped copper oxide nano-crystalline films: as-grown with zinc ions concentration of (a) - Zn(1); (b) - Zn(2); (c) $\mathrm{Zn}(3)$; RTA treated at $525{ }^{\circ} \mathrm{C}$ for $60 \mathrm{~s}$ with zinc concentration (d) $Z n(1)$; (e) - Zn(2); (f) - Zn(3); RTA treated at $725^{\circ} \mathrm{C}$ for $60 \mathrm{~s}$ with zinc concentration (g) - Zn(1); (h) - Zn(2); (i) - Zn(3); TA treated at $450{ }^{\circ} \mathrm{C}$ for 30 min with zinc concentration (j) - Zn(1); (k) - Zn(2); (l) - Zn(3); TA treated at $650{ }^{\circ} \mathrm{C}$ for $30 \mathrm{~min}$ with zinc ions concentration $(\mathrm{m})-\mathrm{Zn}(1)$; (n) $-\mathrm{Zn}(2)$; (o) $-\mathrm{Zn}(3)$. 
some fusions of grain boundaries have occurred (Fig. S5†) leading to a marginal increase in particle size, of about 120-200 $\mathrm{nm}$ with a columnar morphology (Fig. $1 \mathrm{~g}-\mathrm{i}$ and $\mathrm{m}-\mathrm{o}) .{ }^{49} \mathrm{Fig}$. S5 $\dagger$ shows a low magnification TEM image of a Zn-doped copper oxide film. The film consists of accumulated nanocrystals and its thickness amounts to $1 \mu \mathrm{m}$. From the TEM image in Fig. S5, $\dagger$ it is confirmed that the CuO:Zn films are quite porous. We observed several pinholes on the CuO:Zn sample. Typical width and length of the Zn-doped $\mathrm{CuO}$ nanocrystals are $50 \mathrm{~nm}$ and $200 \mathrm{~nm}$, respectively. Such columnar growth in copper oxide has been shown by Richthofen et al. , $^{50}$ but Chauhan et $a .^{49}$ did not observe any preferred grain elongation. The random size and projection distributions of grains, suggest the random nucleation and growth mechanism, and hence an isotropic grain growth. ${ }^{11}$

\section{$\mathrm{X}$-ray diffraction structural analysis}

In all crystallized solid materials, divalent $\mathrm{Cu}$ surroundings are always distorted by a large Jahn-Teller effect which generally leads to square planar groups, which are more stable. ${ }^{52}$ When the $\mathrm{Cu}^{2+}$ ions are substituted by metal $\left(\mathrm{Zn}^{2+}\right)$ ions in the $\mathrm{Zn}^{2+}$ doped copper oxide sample, the difference in ionic $\operatorname{radii}^{53,54}$ between $\mathrm{Cu}^{2+}(r=0.071 \mathrm{~nm})$ and $\mathrm{Zn}^{2+}(r=0.074 \mathrm{~nm})$ leads to deformation of the $\mathrm{CuO}$ lattice and the strain energy may cause dislocations and imperfections in the monoclinic crystal lattice. The formula $\left(\mathrm{Zn}_{x} \mathrm{Cu}_{1-x} \mathrm{O}_{1-l}\right.$, for example $\left.x=0.03\right)$ indicates that $3 \mathrm{wt} \%$ of $\mathrm{Zn}$ atoms replace the copper $(\mathrm{Cu})$ atoms to maintain charge neutrality, some of the oxygen vacancies $\left(\mathrm{V}_{\mathrm{o}}^{*}\right)(l=0.03)$ are created in the system. Therefore, it is reasonable to suggest that due to these reasons, the doped samples could have a higher electrical conductivity.

Fig. 2a shows X-ray powder diffractograms of the as-grown $\mathrm{Cu}_{2} \mathrm{O}$ layers (curve 1) and of the RTA treated ones (RTA525, curves 2-4), where two coexisting phases (cubic $\mathrm{Cu}_{2} \mathrm{O}$ and the monoclinic $\mathrm{CuO}$ ) are detected. The XRD patterns show peaks of both $\mathrm{Cu}_{2} \mathrm{O}$ and $\mathrm{CuO}$ (Fig. 2a, curves 2-4), but the majority phase is the $\mathrm{Cu}_{2} \mathrm{O}$ because the formation of $\mathrm{CuO}$ would be very slow on top of cuprite layers..$^{\mathbf{5 0 5 - 5 7}}$ The comparison of the respective peak intensity of specimens after RTA at $525{ }^{\circ} \mathrm{C}$ shows that the $\mathrm{Cu}_{2} \mathrm{O}$ amount is higher when compared to CuO layers (Fig. 2a, curves 2-4). In the XRD pattern of TA650 and RTA725 specimens, all XRD peaks are indexed completely to the $\mathrm{CuO}$ monoclinic symmetry ${ }^{54,55}$ (JCPDS 45-0937, as presented in Fig. 2b, curves 2-4). X-ray powder diffractograms of all samples showed the same features. The peak at $2 \theta=36.4^{\circ}$ is strongest and was indexed to the $\mathrm{Cu}_{2} \mathrm{O}(111)$ crystal plane, and other peaks at $2 \theta=29.6^{\circ}, 42.3^{\circ}, 61.4^{\circ}, 73.6^{\circ}$ and $77.4^{\circ}$ are also in good agreement with the diffraction pattern of the $\mathrm{Cu}_{2} \mathrm{O}$ cubic phase $^{54,55}$ (JCPDS 05-0667, as presented in Fig. 2). Even if $\mathrm{CuO}$ peaks are weaker compared to $\mathrm{Cu}_{2} \mathrm{O}$ peaks on the sides of the strongest peak two bands at $2 \theta=35.5^{\circ}$ and $38.7^{\circ}$ indexing to the $(-111) /(002)$ and (111) planes (see Fig. 2a, curves 2-4) of the monoclinic $\mathrm{CuO}$ can be observed, respectively. The spectra modifications should be due to a removal process of the $\mathrm{Cu}_{2} \mathrm{O}$ phase on the specimens. ${ }^{55}$ The effect of rapid thermal annealing at $725{ }^{\circ} \mathrm{C}$ for $60 \mathrm{~s}$ on the structure of $\mathrm{CuO}$ layers doped with different concentrations of zinc is presented in Fig. $2 \mathrm{~b}$.
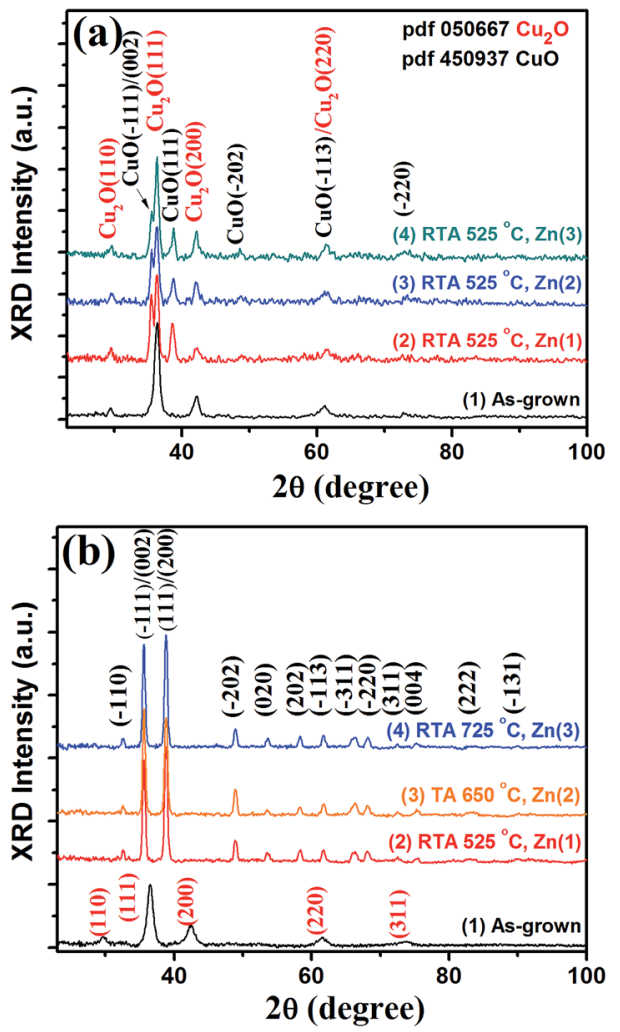

Fig. 2 X-ray powder diffractograms of $\mathrm{Zn}_{x} \mathrm{Cu}_{1-x} \mathrm{O}_{1-l}$ layers: (a) asgrown (1) and rapid thermal annealed (RTA) in air at $525^{\circ} \mathrm{C}$ for $60 \mathrm{~s}$. Curves 2, 3, 4 correspond to different concentrations $Z n(1), Z n(2)$, and $\mathrm{Zn}(3)$ of $\mathrm{Zn}$-doped copper oxide; (b) as-grown (1), RTA at $525^{\circ} \mathrm{C}$ (2) and $725^{\circ} \mathrm{C}$ (4) for $60 \mathrm{~s}$, and thermal annealed in air at $650{ }^{\circ} \mathrm{C}$ (3) for 30 min. Curves 2, 3, 4 correspond to different concentrations Zn(1), Zn(2), and $\mathrm{Zn}(3)$ of $\mathrm{Zn}$-doped copper oxide layers.

The oxide average crystallite sizes are computed from DebyeScherer's equation from the broadening of diffraction lines $(-111)$ and $(111):^{54,55,58}$

$$
D_{h k l}=\frac{0.9 \lambda}{\beta \cos \theta}
$$

where $\lambda$ is the X-ray wavelength, $\beta$ - the full width at half maximum (FWHM) of the diffraction peak, $D_{h k l}$ - the average crystallite size, and $\theta$ - the Bragg angle. The grain sizes are calculated by using the peaks corresponding to the $(-111)$ plane of CuO:Zn, which are $3.23 \mathrm{~nm}, 3.46$, and $3.63 \mathrm{~nm}$ for samples RTA annealed at $725^{\circ} \mathrm{C}$ and doped with concentrations \#1, \#2, and \#3, respectively. The mid-crystallite size increases slightly with increasing concentration of $\mathrm{Zn}$ in the materials. It can be caused by higher ionic mobility and lower activation energy of zinc ions. ${ }^{56}$ As a result it leads to a larger crystallite size due to easier transfer of $\mathrm{Zn}$ ions from trapping sites to nucleation sites in the growth of crystallites. ${ }^{56}$ The grain sizes calculated by using the peak corresponding to the (111) plane of CuO:Zn are $3.27 \mathrm{~nm}, 3.15 \mathrm{~nm}$, and $3.14 \mathrm{~nm}$ for samples doped with concentrations $\# 1, \# 2$, and \#3, respectively, after RTA at $725{ }^{\circ} \mathrm{C}$. Note that the FWHM of the peak is obtained by fitting the XRD patterns using software Rayflex. ${ }^{7}$ 
For samples marked as RTA525, the sizes of $\mathrm{Cu}_{2} \mathrm{O}$ aggregates $D_{111}$ are 2.43, 2.29 and $1.09 \mathrm{~nm}$, for $\mathrm{Zn}$-doping concentrations 1 , 2,3 , respectively. This is consistent with the corresponding SEM images of the $\mathrm{CuO}$ nanocrystals (see Fig. S3†). It was observed that the $\mathrm{Cu}_{2} \mathrm{O}$ aggregates increase in size with the treatment temperatures, but decrease with the doping level. For $\mathrm{CuO}$, the aggregate sizes $D_{111}$ are $2.43,2.39$, and $1.47 \mathrm{~nm}$, for samples doped with concentrations $\# 1, \# 2$, and $\# 3$, respectively (sample sets TA650-treated).

The information on the structural characteristics of the $\mathrm{CuO}$ nano-crystalline layers were obtained by computing the strain $(\varepsilon)$, the average crystallite size $(D)$, as well as the dislocation density $(\delta)$ according to the relations: ${ }^{\mathbf{9 9 , 6 0}}$

$$
\begin{gathered}
\varepsilon=\frac{\beta \cos \theta-\frac{\lambda}{D}}{\sin \theta} \\
\frac{\beta \cos \theta}{\lambda}=\frac{1}{D}+\frac{\varepsilon \sin \theta}{\lambda} \\
\delta=\frac{1}{D^{2}}
\end{gathered}
$$

where $\beta$ is the FWHM and $\theta$ is the diffraction angle.

Lattice parameters $\left(a \neq b \neq c, \alpha=\gamma=90^{\circ} \neq \beta\right.$ for monoclinic structure) and the unit cell volume for the $\mathrm{CuO}$ layers were found by following the equations: ${ }^{61}$

$$
\begin{gathered}
\frac{1}{d^{2}}=\frac{1}{\sin ^{2} \beta}\left(\frac{h^{2}}{a^{2}}+\frac{k^{2} \sin ^{2} \beta}{b^{2}}+\frac{l^{2}}{c^{2}}-\frac{2 h l \cos \beta}{a c}\right) \\
V=a b c \sin \beta
\end{gathered}
$$

The calculated structural parameters of the $\mathrm{Zn}$-doped copper oxide thin films indicate no significant changes in values. According to the $\mathrm{XRD}$ results, the $\mathrm{Zn}$-doped $\mathrm{CuO}$ samples contain no detectable impurities, but the lattice parameters slightly differ from those of pure $\mathrm{CuO}$ (the $a$ parameter is increased and the $b$ parameter is decreased) which can be interpreted as an indicator that $\mathrm{Zn}$ is incorporated in the $\mathrm{CuO}$ lattice as discussed before. ${ }^{\mathbf{6 2 , 6 3}}$ There are no additional peaks of Zn impurities, suggesting that the Zn-doping did not modify the original CuO lattice. ${ }^{62,63}$ Therefore, it could be also suggested that the $\mathrm{Zn}^{2+}$ ions are spread in the $\mathrm{CuO}$ matrix. ${ }^{64}$ In addition, the lattice constants are determined using the least square refinement method in the unit cell program. The obtained parameters of the doped sample are: $a=4.6871 \AA$, $b=3.4252 \AA$, and $c=5.1333 \AA$, and the unit cell volume is $81.3110 \AA^{3}$. The lattice constants of the doped sample are the monoclinic data of undoped $\mathrm{CuO}(a=4.6877 \AA$, $b=3.4266 \AA$, $c=5.1328 \AA$, unit cell volume $=81.2979 \AA^{3}$ ) obtained under the same conditions. It can be seen that the length of both $a$-axis and $b$-axis of doped samples shrink, while $c$-axis expand with the $\mathrm{Zn}^{2+}$ ion doping in $\mathrm{CuO}$ because the ionic radius of $\mathrm{Cu}^{2+}$ ion $(0.71 \AA)$ is smaller than that of $\mathrm{Zn}^{2+}$ ion ( $\left.0.74 \AA\right)$. However, it is speculated that $\mathrm{Zn}^{2+}$ ions are indeed incorporated into the $\mathrm{CuO}$ lattice and replaced some of the $\mathrm{Cu}$ ions to form solid solutions of $\mathrm{Zn}_{x} \mathrm{Cu}_{1-x} \mathrm{O}$ with low doping amount of $\mathrm{Zn}^{2+}$ ions $(x=0.03)$.
As annealing temperature increases $\left(450-650{ }^{\circ} \mathrm{C}\right.$ for TA and 525-725 ${ }^{\circ} \mathrm{C}$ for RTA), the crystalline nature of $\mathrm{CuO}$ has been improved indicated by enhanced intensity of the corresponding XRD peaks. ${ }^{65}$ However, with further increase in temperature up to $650{ }^{\circ} \mathrm{C}$ for TA and $725^{\circ} \mathrm{C}$ for RTA samples, a slight decrease in crystallinity was observed (not shown here). The strain values were calculated with eqn (4) by using the peak corresponding to the (111) plane of $\mathrm{Zn}$-doped $\mathrm{CuO}$ films, and the resultant are $-0.077,-0.094$, and -0.112 , respectively, for samples doped with concentrations \#1, \#2, and \#3 after RTA annealing at $725{ }^{\circ} \mathrm{C}$. The strain values are $-0.149,-0.265$, and -1.499 , respectively, for samples doped with concentrations \#1, \#2, and \#3 after RTA at $525{ }^{\circ} \mathrm{C}$. The negative sign indicates that it is compressive by nature. The dislocation density for SCS samples is determined to be decreased with increasing $\mathrm{Zn}$ concentration. As well as, structural studies of the SCS/RTA thin films reveal that the diffraction angle and the corresponding $d$ value of the lattice spacing of the layers changes slightly with variation in $\mathrm{Zn}$ content. ${ }^{56}$ The decrease in the $\beta$ value of the (111) peak indicates on the crystallite size growth RTA at $725{ }^{\circ} \mathrm{C}$ and with zinc doping with concentrations \#1, \#2, and \#3, respectively. The main motive of crystallite size increase is associated with strain and indicates a reduction in concentration of lattice imperfections. ${ }^{56}$

According to XRD experimental results, a negligible lattice deformation was found for $\mathrm{Zn}$-doped $\mathrm{CuO}$ due to ionic radii difference. It may be a result of shorter $\mathrm{Cu}_{\mathrm{Zn}}-\mathrm{O}$ bonds and smaller $\left[\mathrm{Cu}_{\mathrm{Zn}} \mathrm{O}_{4}\right]$ units in nano-crystals. ${ }^{54}$ In Fig. $2 \mathrm{~b}$, there is a very small shift $\left(\sim 0.026^{\circ}\right)$ to a higher $2 \theta$ angle value of the ( $\left.\begin{array}{lll}0 & 0 & 2\end{array}\right)$ XRD peaks for low $\mathrm{Zn}$-doped $\mathrm{CuO}$ with respect to those of pure CuO. No essential change in the crystalline structure was observed, which indicates that most $\mathrm{Cu}$ atoms are in the $\mathrm{CuO}$ lattice.

\section{Micro-Raman studies of doped samples}

Copper(II)oxide (CuO) has a monoclinic structure and affiliate with the $C_{2 h}^{6}$ space group (two molecules for every primitive cell). ${ }^{66}$ It has twelve phonon branches since there are four atoms in the primitive cell. ${ }^{67}$ The zone-centre optical-phonon modes are $\Gamma=\mathrm{A}_{\mathrm{g}}+2 \mathrm{~B}_{\mathrm{g}}+4 \mathrm{~A}_{\mathrm{u}}+5 \mathrm{~B}_{\mathrm{u}} \cdot{ }^{68}$ Among them, there are nine optical modes, from which three modes $\left(\mathrm{A}_{\mathrm{g}}+2 \mathrm{~B}_{\mathrm{g}}\right)$ are Raman active, ${ }^{\mathbf{6 8 , 6 9}}$ other six ones $3 \mathrm{~A}_{\mathrm{u}}+3 \mathrm{~B}_{\mathrm{u}}$ are infrared active. ${ }^{67}$ Furthermore, there are normally three acoustic modes, which are of $A_{u}+2 B_{u}$ symmetry. In the $A_{g}$ and $B_{g}$ Raman modes the oxygen atoms move in $b$-direction for $\mathrm{A}_{\mathrm{g}}$ and perpendicular to the $b$-axis for $\mathrm{B}_{\mathrm{g}}$ modes. ${ }^{67}$ However, the IR modes implicate motion of both $\mathrm{O}$ and $\mathrm{Cu}$ atoms and the dipole moment is along the $b$-axis for the $\mathrm{A}_{\mathrm{u}}$ modes, but perpendicular to it in case of the $B_{u}$ modes. ${ }^{67}$

Fig. 3 shows a micro-Raman spectra of various samples (RTA-annealed and TA-annealed) with CuO:Zn nanomaterials. Three micro-Raman peaks were observed in sample $\mathrm{c} 1$, at about 288,330 and $621 \mathrm{~cm}^{-1}$. With an increase in grain size (samples after TA treatment at $650{ }^{\circ} \mathrm{C}$, see Fig. $1 \mathrm{~m}-\mathrm{O}$ and $3 \mathrm{~b}$ ), these microRaman peaks become higher, and move slightly to larger wavenumbers. ${ }^{69}$ A shift to $292 \mathrm{~cm}^{-1}$ and $295 \mathrm{~cm}^{-1}$ was found in samples c2 and c3, and the FWHM of the peak was decreased 
from 21 to 11 and $7 \mathrm{~cm}^{-1}$, respectively. The broadening and red shift of the micro-Raman spectra happens with a decrease in the grain size. ${ }^{69}$ The micro-Raman curves show three main phonon modes in the crystallite-like $\mathrm{CuO}$ nanomaterials, at 288, 335 and $624 \mathrm{~cm}^{-1}$, interrelated to the $A_{g}, B_{1 g}$ and $B_{2 g}$ symmetries, ${ }^{70}$ respectively.

Fig. 3 confirms continuous red-shift and the broadening of the $\mathrm{A}_{\mathrm{g}}$ phonon mode when the $\mathrm{Zn}$ concentration was increased. Based on reports, ${ }^{69,71,72}$ the phonon modes in $\mathrm{CuO}$ single crystal shift to a lower frequency mode and the linewidth is found to broadened as a result of the nanodimensions effect. ${ }^{73}$

Coexistence of mixed phases, namely cuprite $\mathrm{Cu}_{2} \mathrm{O}: \mathrm{Zn}$ and tenorite $\mathrm{CuO}: \mathrm{Zn}$ were observed in our samples. It is considered that the peak shifts as the nanoparticle diameter changes, ${ }^{70}$ also the size effects of phonon-electron coupling ${ }^{74}$ and the polarization dependence of Raman phonon modes play an important role in the Raman shifts and lead to unconventional properties. $^{70}$ Comparing the Raman spectra of $\mathrm{CuO}$ powder ${ }^{68}$ and single crystal, ${ }^{71}$ we note the micro-Raman peak at $288 \mathrm{~cm}^{-1}$ as $\mathrm{A}_{\mathrm{g}}$ and 330 and $621 \mathrm{~cm}^{-1}$ as $\mathrm{B}_{\mathrm{g}}$ modes. These wavenumbers are slightly different in comparison with those in the scientific literature $\left(298,345\right.$ and $\left.632 \mathrm{~cm}^{-1}\right)$ due to size effects. ${ }^{69}$ However, in sample $\mathrm{c} 3$ when the grain size is larger, micro-Raman peaks have been observed at 296, 342, and $628 \mathrm{~cm}^{-1}$, which corresponds to bulk $\mathrm{CuO}$. No $\mathrm{Cu}_{2} \mathrm{O}$ modes are present in the
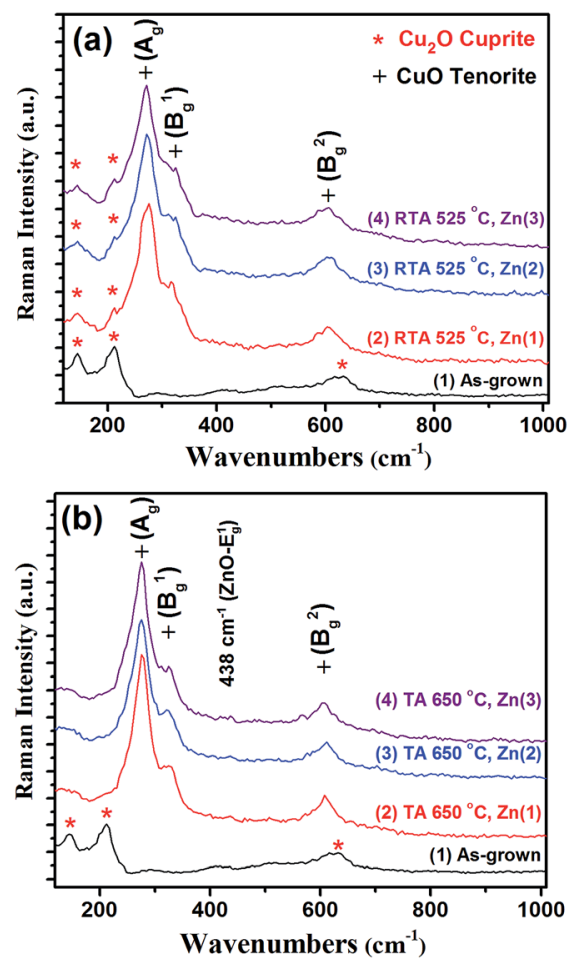

Fig. 3 Series of micro-Raman spectra scanned of copper oxide nanocrystallites doped with different concentrations (Zn(1), Zn(2), $\mathrm{Zn}(3))$ of zinc presenting the phonon modes in the top of the nanostructures corresponding to the $A_{g}, B_{1 g}$ and $B_{2 g}$ symmetries, respectively. Typical micro-Raman spectra of the: (a) $\mathrm{CuO} / \mathrm{Cu}_{2} \mathrm{O}$ nanocrystallites RTA-annealed at $525{ }^{\circ} \mathrm{C}$ for $60 \mathrm{~s}$; (b) $\mathrm{CuO}$ nanocrystallites TA-annealed at $650^{\circ} \mathrm{C}$ for $30 \mathrm{~min}$. samples after TA650-treatment, demonstrating single phase characteristics of our $\mathrm{CuO}$ nanomaterials. The bands at about 301,347 and $633 \mathrm{~cm}^{-1}$, may be assigned to the $A_{g}\left(296 \mathrm{~cm}^{-1}\right)$, $B_{g(1)}\left(346 \mathrm{~cm}^{-1}\right)$ and $B_{g(2)}\left(631 \mathrm{~cm}^{-1}\right)$ modes and are in agreement with previous data. ${ }^{71,75}$ The absence of $\mathrm{Cu}_{2} \mathrm{O}$ modes ${ }^{76}$ in the micro-Raman studies of the specimens confirms the phase purity of the nanocrystals after annealing at $650{ }^{\circ} \mathrm{C}$ (TA650).

Secondary ion mass spectroscopy (SIMS) shows (see Fig. S6†) that while the concentrations of $\mathrm{Cu}$ and $\mathrm{O}$ remain constant as a function of depth, the $\mathrm{Zn}$ concentration varies rapidly as a function of depth and its behaviour seems to track that of the $\mathrm{Si}$ substrate. It is possible that the SIMS signal of $\mathrm{Zn}$ maybe contaminated by the Si signal.

\section{Gas sensing response}

For gas sensing investigations the fabricated gas sensor structures are mounted in a test chamber at the required operating temperature for $30 \mathrm{~min}$ before exposing to the designated gases in order to stabilize the electrical baseline. Reported data in literature demonstrates good selectivity and gas response of the copper oxide based sensors to ethanol vapours. ${ }^{\mathbf{1 4 2 0}}$ Thus, we select hydrogen gas (100 ppm) and ethanol vapour (100 ppm) as our test gases to demonstrate changes in selectivity of the Zn-doped copper oxide based nano-crystalline films. The gas response is presented as $S=\Delta R / R_{\text {air }} \times 100 \%$, assuming $\Delta R=R_{\text {gas }}-R_{\text {air }}, R_{\text {gas }}$ and $R_{\text {air }}$ are the resistances of the sensor specimen under gas exposure and in ambient air, respectively.

In this work, gas sensing properties are investigated mainly in dependence of $\mathrm{Zn}$ concentration in copper oxide nano-crystallite films ( $1 \mu \mathrm{m}$ thick). In order to determine the influences of Zn dopant content on gas sensing performances of copper oxide films, three concentrations are studied as presented above. More detailed investigations on the effect of treatment type and thickness of nano-crystalline films, as well as detailed gas sensing mechanism are reported partly in paper, ${ }^{81}$ as well as will be reported in future work.

Fig. 4a shows the gas response of the copper oxide samples with 2.8-3.0 wt\% $\mathrm{Zn}$ to $\mathrm{H}_{2}$ gas and $\mathrm{C}_{2} \mathrm{H}_{5} \mathrm{OH}$ versus type of thermal annealing: as-grown $\mathrm{Cu}_{2} \mathrm{O}$ samples, TA450 and TA650-treated with $2.8 \mathrm{wt} \% \mathrm{Zn}$ at operating temperature (OPT) of $400{ }^{\circ} \mathrm{C}$, and RTA525 and RTA725-annealed with $3.0 \mathrm{wt} \% \mathrm{Zn}$ at OPT of $300{ }^{\circ} \mathrm{C}$. As-grown Zn-doped copper oxide samples demonstrated poor gas response and selectivity to hydrogen gas, $S_{\mathrm{H}_{2}} \sim 42 \%$ and $S_{\mathrm{EtOH}} \sim 23 \%$, while thermal annealing improved the gas sensing characteristics of the fabricated sensor specimens. The highest gas response of the RTA sample set annealed at $525{ }^{\circ} \mathrm{C}$ with $S_{\mathrm{H}_{2}} \sim 756 \%$ and $S_{\mathrm{EtOH}} \sim 79 \%$ was found, having a good selectivity to hydrogen gas versus ethanol $\left(S_{\mathrm{H}_{2}} / S_{\mathrm{EtOH}} \approx 9.5\right)$. Also, we investigated thermal annealing at $650{ }^{\circ} \mathrm{C}$ (samples TA650) and rapid treatment at $525^{\circ} \mathrm{C}$ (samples RTA525).

Fig. $4 \mathrm{~b}$ shows the response of sensor structure to hydrogen gas versus concentration of $\mathrm{Zn}$ dopant: $\mathrm{Zn}(1)-1.9 \mathrm{wt} \% \mathrm{Zn} ; \mathrm{Zn}(2)$ - $2.7 \mathrm{wt} \% \mathrm{Zn} ; \mathrm{Zn}(3)-3.0 \mathrm{wt} \% \mathrm{Zn}$ in the case of RTA treated samples, as well as of $\mathrm{Zn}(1)-1.9 \mathrm{wt} \% \mathrm{Zn}, \mathrm{Zn}(2)-2.4 \mathrm{wt} \% \mathrm{Zn}$; 

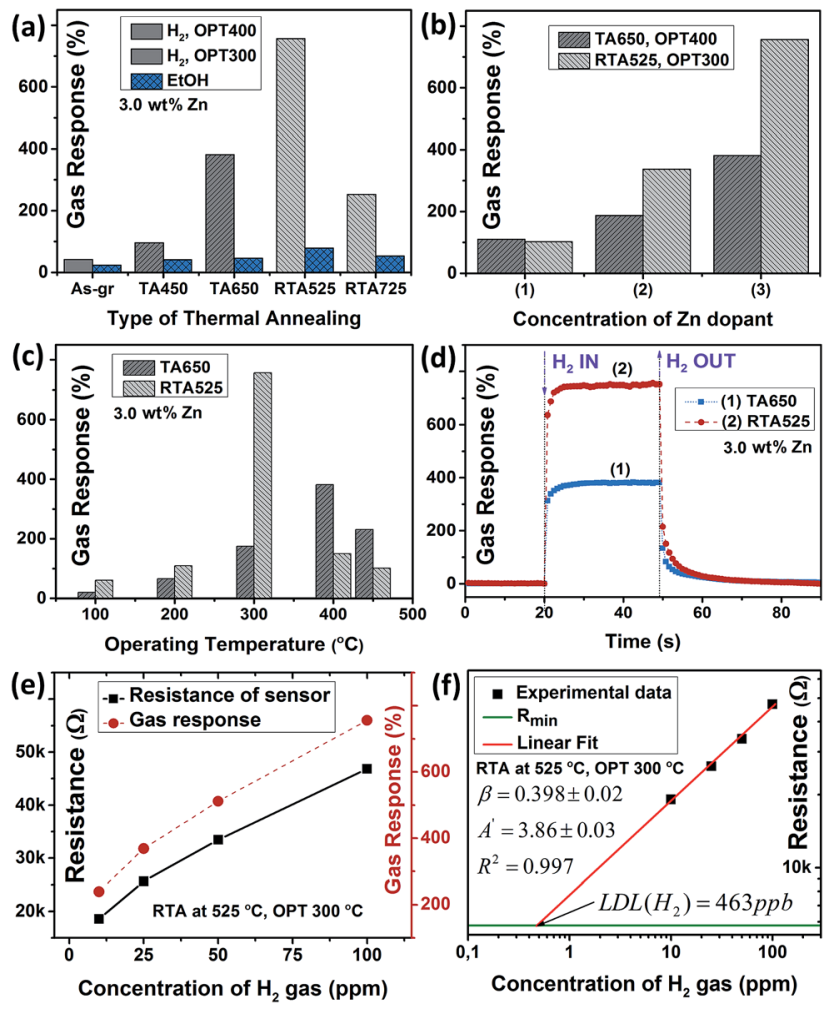

Fig. 4 (a) Gas response of the copper oxide samples with 2.8-3.0 wt\% $\mathrm{Zn}$ doping level versus type of thermal annealing: as-grown $\mathrm{Cu}_{2} \mathrm{O}$ samples (As-gr), TA-treated at $450^{\circ} \mathrm{C}$ (TA450) and at $650{ }^{\circ} \mathrm{C}$ (TA650) at operating temperature (OPT) of $400{ }^{\circ} \mathrm{C}$, RTA-treated at $525{ }^{\circ} \mathrm{C}$ (RTA525) and at $725^{\circ} \mathrm{C}$ (RTA725) at OPT $300^{\circ} \mathrm{C}$. (b) Gas response of the sensor to $\mathrm{H}_{2}$ versus content of $\mathrm{Zn}$, for TA650 and RTA525. (c) Gas response to $\mathrm{H}_{2}$ versus OPT of the samples with $\mathrm{Zn}(3)$ doping level. (d) The dynamic response of TA650 (curve 1) and RTA525 (curve 2) toward $\mathrm{H}_{2}$ at OPT of $400{ }^{\circ} \mathrm{C}$ and $300{ }^{\circ} \mathrm{C}$, respectively. (e) Resistance and gas response of sensor toward concentrations of $\mathrm{H}_{2}$ for RTA525 at OPT $300{ }^{\circ} \mathrm{C}$ with $\mathrm{Zn}(3)$ doping level; (f) estimation of the lowest detection limit for $\mathrm{H}_{2}$ detection using log vs. log plot.

$\mathrm{Zn}(3)-2.8 \mathrm{wt} \% \mathrm{Zn}$ in the case of TA treated samples. As expected, the gas response of the $\mathrm{Zn}$-doped copper oxide based sensors increases as $\mathrm{Zn}$ doping concentration increases for both types of treatments, which indicates that the main factor in hydrogen gas response change is the dopant in the nanomaterial.

The optimal operating temperature (OPT) of the fabricated sensors was also investigated. Fig. 4c shows the gas response to hydrogen gas $v s$. OPT for the samples doped with concentration $\mathrm{Zn}(3)$. As observable, the OPT is higher for TA650-treated specimens when compared to the case of RTA525, $400{ }^{\circ} \mathrm{C}$ versus $300{ }^{\circ} \mathrm{C}$, respectively. The lowest OPT is preferable for lower power consumption of the sensor heaters, thus it is a very important parameter from the industrial point of view. However, the gas response and rapidity of the sensor is strongly dependent on the OPT value., ${ }^{\mathbf{6 , 1 4 2 0}}$ At low operating temperatures of below $200{ }^{\circ} \mathrm{C}$, the hydrogen gas molecules do not possess sufficient thermal energy to react with the adsorbed oxygen molecules $\left(\right.$ e.g. $\mathrm{O}_{2}{ }^{-}$) on the surface of copper oxide, which lead to low reaction rate and lower gas response. ${ }^{77}$ At OPT higher than $300{ }^{\circ} \mathrm{C}$ the oxygen atoms mainly adsorb at the surface of copper oxide nano-crystallites. ${ }^{\mathbf{1 4 2 0 , 7 7}}$ In this case, the thermal energy is sufficient to overcome the activation energy barrier of the reaction of the hydrogen molecules with ionosorbed oxygen species. ${ }^{20,77}$

Fig. 4d shows the dynamic response of sensor structures on copper oxide nano-crystalline films treated TA650 and RTA525 toward hydrogen gas at OPT of $400{ }^{\circ} \mathrm{C}$ and $300{ }^{\circ} \mathrm{C}$, respectively. The calculated response $\tau_{\mathrm{r}}$ and recovery $\tau_{\mathrm{d}}$ times (as time to accomplish $90 \%$ of the full gas response and time to take $10 \%$ of full recovery to initial baseline value, respectively) are $\tau_{\mathrm{r}} \sim 1.9 \mathrm{~s}$ and $\tau_{\mathrm{d}} \sim 8.5 \mathrm{~s}$ for TA650-treated sample at OPT of $400{ }^{\circ} \mathrm{C}$, while for the RTA525 treated one at lower OPT value was $\tau_{\mathrm{r}} \sim 2.4 \mathrm{~s}$ and $\tau_{\mathrm{d}} \sim 6.9 \mathrm{~s}$, respectively. However, at the same OPT the RTA treated samples are faster, for example at $400{ }^{\circ} \mathrm{C}$ the $\tau_{\mathrm{r}} \sim 1.4 \mathrm{~s}$ and $\tau_{\mathrm{d}} \sim 5.4 \mathrm{~s}$. All data on rapidity of the sensors are included in Table S1. $\uparrow$ The best thermal annealing regime to obtain higher gas response and faster response/recovery from CuO:Zn films is RTA at $525{ }^{\circ} \mathrm{C}$ for $60 \mathrm{~s}$.

Fig. 4e shows the results on sensor resistance and gas response versus concentration of hydrogen gas $\left(p_{\mathrm{H}_{2}}\right)$ of the sample treated RTA525 and measured at OPT of $300{ }^{\circ} \mathrm{C}$ with $\mathrm{Zn}(3)$ doping level and it is observed that the response follows a power law relationship on gas concentration $S_{\mathrm{H}_{2}} \propto p_{\mathrm{H}_{2}}{ }^{\beta}$, where $\beta$ is the slope of $\log R v s$. $\log p_{\mathrm{H}_{2}}$, and $\beta=0.398$ (see Fig. 4f), ${ }^{14}$ which is in concordance with different results on copper oxide based sensors. ${ }^{6}$ Fig. $4 \mathrm{f}$ shows the estimation of lowest detection limit (LDL) using the method reported by Volanti et al. ${ }^{6} R_{\min }$ is defined as $R_{\text {min }}=R_{\text {air }}+3 \sigma_{0}$, where $R_{\text {air }}$ is the resistance in air before exposure to hydrogen gas at OPT of $300{ }^{\circ} \mathrm{C}$, and $\sigma_{0}$ is the standard deviation of the air response. ${ }^{6}$ For calculation of $\sigma_{0}$, the sensor was placed in the test chamber at OPT of $300{ }^{\circ} \mathrm{C}$ for $60 \mathrm{~min}$, in order to stabilize the sensor resistance, and then the next $60 \mathrm{~min}$ before exposing to hydrogen gas are used to calculate $\sigma_{0}$. In this work we found that $\sigma_{0}=5.43 \Omega$ and $R_{\min }=5471 \Omega$.

The parameters obtained by linear fitting of the $\log v s$. $\log$ plot are presented in Fig. 4f. Estimated LDL was $\sim 0.5 \mathrm{ppm}$ of hydrogen gas which was comparable to one of the best values for $\mathrm{CuO}$ hydrogen gas based sensor reported in literature. ${ }^{6} \mathrm{We}$ note the relatively low value of $R_{\min }$ (in the order of $\mathrm{k} \Omega$ ), which is important during film integration in electronic devices for gas detection applications. Usually, to increase the gas response to reducing gases in case of sensors based on n-type oxide metals, one uses acceptor doping which decreases the concentration of the electrons in the semiconductor ${ }^{16,78}$ and leads to an increase in total resistance of the sensor (to $\mathrm{M} \Omega$ range). ${ }^{79}$ As a result, the sensing measurements in laboratory conditions are possible only with high precision test measurements tools in the majority of cases. Thus, the integration in a sensor module is a problem due to the necessity of amplifiers with very high input impedance as result of the high resistance of the sensors. Therefore the total cost of the device increases. In our case, a $\mathrm{k} \Omega$ range of the sensor resistance value can solve those problems. Also, the fast response and recovery times associated with high gas response and selectivity to hydrogen gas, demonstrated 
good potential for fabrication of stable, robust, low-cost and fast hydrogen gas sensor applications.

According to literature analysis, sensors based on copper oxide or other p-type metal oxide nanostructures with such high response and selectivity to hydrogen have not been reported until now by other research groups. In most cases, p-type semiconductor based sensors demonstrated good gas response to ethanol vapour and other VOCs, such as benzene acetone and toluene. ${ }^{16}$ For comparison, in Table $\mathrm{S} 2 \uparrow$ the most relevant data on the hydrogen gas sensors based on p-type and n-type oxide metal nanostructures which indicate response to hydrogen gas and ethanol vapour ratio have been presented in detail.

\section{The effect of humidity on the gas sensitivity}

To check the influence of the humidity on gas sensing performances of the copper oxide based nanostructured films, gas sensing measurements were performed in $90 \% \mathrm{RH}$ and compared with those in $30 \% \mathrm{RH}$ for samples treated RTA at $525{ }^{\circ} \mathrm{C}$ and TA at $650{ }^{\circ} \mathrm{C}$ with $3.0 \mathrm{wt} \% \mathrm{Zn}$ (Fig. 5a and b). As can be observed, the gas response decreased in humid atmosphere by $\approx 35 \%$ and $\approx 65 \%$ for $\mathrm{RTA}$ and $\mathrm{TA}$ treated samples, respectively. Also a decrease in rapidity of the sensors can be observed (see Table S1 $\dagger$ ). Thus, the improved stability to humidity of the RTA treated samples is indicated. One of the main possible reasons could be a lower response to water vapour of the RTA treated samples (see Fig. S7†), while the decrease in gas response can be attributed to competition of

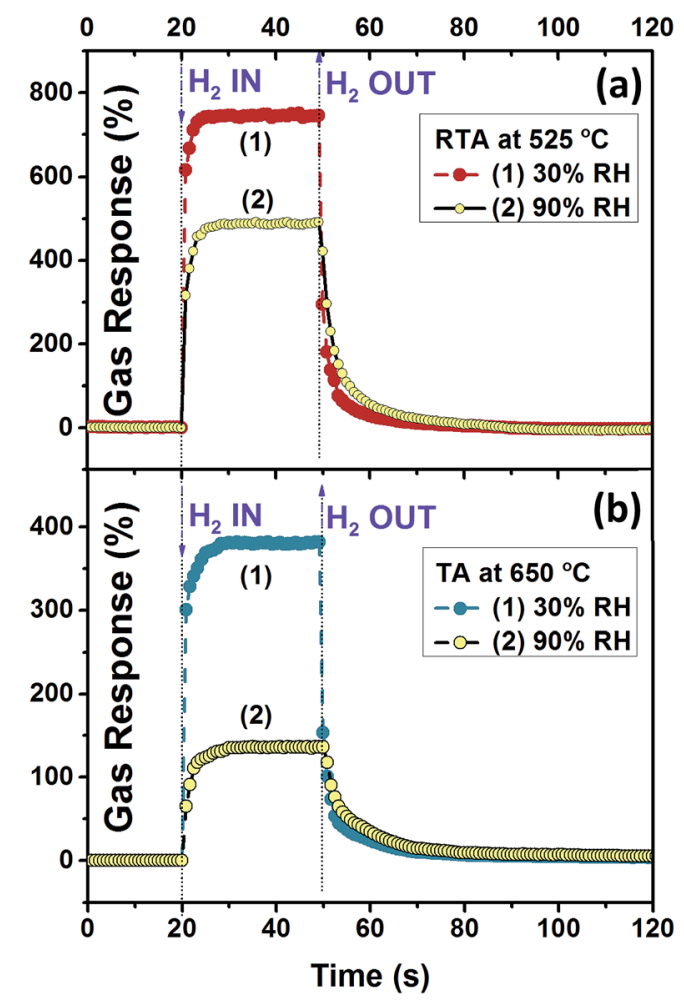

Fig. 5 Dynamic hydrogen gas response of the samples treated RTA at $525^{\circ} \mathrm{C}$ (operating temperature $300{ }^{\circ} \mathrm{C}$ ) and TA-annealed at $650{ }^{\circ} \mathrm{C}$ (operating temperature $400{ }^{\circ} \mathrm{C}$ ) in $30 \%$ and $90 \% \mathrm{RH}$. adsorbed oxygen species on the surface of the $\mathrm{CuO}$ nanocrystals between water vapour and $\mathrm{H}_{2}$ molecules. ${ }^{80}$ More details on the influence of humidity on gas sensing performances of the Zn-doped copper oxide nanostructured films versus concentration of $\mathrm{Zn}$ and related mechanism have been presented in previous work. ${ }^{81}$

\section{Gas sensing mechanism proposed}

The reactivity of active sites on the surface of $\mathrm{Zn}$-doped copper oxide nano-crystalline films is strongly dependent on its doping concentration, type of defects and impurities. ${ }^{78}$ Thus, surface phenomena are important to understand the sensing mechanism of the sensor based on p-type semiconductor nanomaterials. As we mentioned above, adsorbed oxygen can be ionized into several forms, namely atomic $\mathrm{O}^{-}$or $\mathrm{O}^{2-}$ and molecular $\mathrm{O}_{2}{ }^{-82}$ At temperatures below $200{ }^{\circ} \mathrm{C}$, predominant surface oxygen species are in molecular form $\mathrm{O}_{2}{ }^{-}:^{83}$

$$
\begin{gathered}
\mathrm{O}_{2(\mathrm{~g})} \rightarrow \mathrm{O}_{2(\mathrm{ad})} \\
\mathrm{O}_{2(\mathrm{ad})} \rightarrow \mathrm{O}_{2(\mathrm{ad})}{ }^{-}+\mathrm{h}_{\text {(lattice) }}^{+}
\end{gathered}
$$

While at temperatures above $200{ }^{\circ} \mathrm{C}$ predominant surface oxygen species are atomic species $\mathrm{O}^{-}$and $\mathrm{O}^{2-}:^{21}$

$$
\frac{1}{2} \mathrm{O}_{2(\mathrm{ad})} \rightarrow \mathrm{O}_{(\mathrm{ad})}{ }^{-}+\mathrm{h}_{(\text {lattice })}{ }^{+} \text {. }
$$

Ionosorbed oxygen creates the surface acceptor states and traps electrons from the valence band, which results in increased concentration of holes and resistance decreases (for p-type semiconductors). ${ }^{80} \mathrm{~A}$ schematic illustration of the proposed gas sensing mechanism is presented in Fig. $6 \mathrm{a}$ and $\mathrm{b}$, where the transparent blue zone shows HAL with lower resistance in comparison with core region (represented by dark yellow region). At exposure to hydrogen gas the following reaction occurs (taking in account that $\mathrm{h}^{+}+\mathrm{e}^{-}=$null): ${ }^{14}$

$$
\mathrm{H}_{2(\mathrm{~g})}+\mathrm{O}_{(\mathrm{ads})}{ }^{-}+\mathrm{h}^{+} \rightarrow \mathrm{H}_{2} \mathrm{O}_{(\mathrm{g})}+\text { null }
$$

Equation (12) is represented schematically in Fig. 6b. With decrease in the holes concentration, HAL width becomes thinner and the resistance of the sensor structure increases respectively.

Electron sensitization is known to be an efficient tool to control/tune the gas response and selectivity of the oxide metals with both types of electrical conductivity. ${ }^{78}$ In our case it is performed by control of $\mathrm{Zn}$ concentration in copper oxide nanocrystalline films. It has been shown that addition of zinc in copper oxide films decreases the electrical resistivity of the sensing material. ${ }^{13,81}$ For example, in the case of RTA at $525{ }^{\circ} \mathrm{C}$ the electrical resistivity of the sample was decreased from $3.1 \times 10^{4} \Omega \mathrm{cm}$ to $1.95 \times 10^{4} \Omega \mathrm{cm}$ by increasing $\mathrm{Zn}$ concentration from (\#1) to (\#3). The created acceptor centres are ionized at room temperature by capturing electrons from the valence band and generating holes. In general, it is assumed that $\mathrm{Zn}$-doping of $\mathrm{Cu}_{2} \mathrm{O}$ results in donor doping. ${ }^{84}$ 


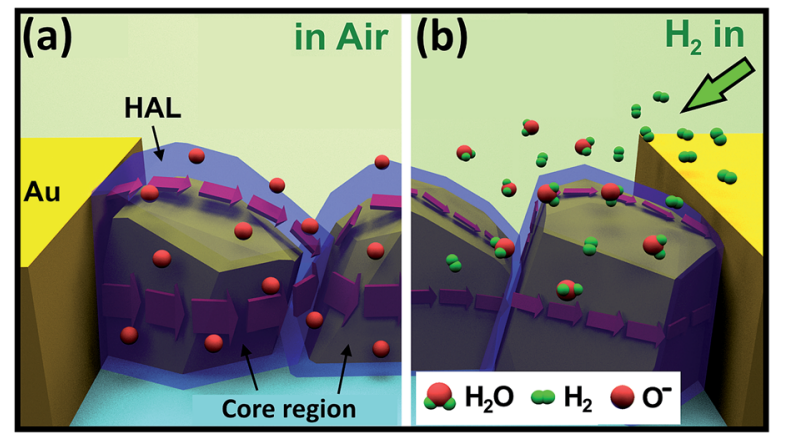

Fig. 6 Schematic representation of $\mathrm{H}_{2}$ gas sensing mechanism for gas sensor based on $\mathrm{Zn}$-doped copper oxide nano-crystalline films. (a) At exposure to ambient air, the oxygen atoms (illustrated by red spheres) are adsorbed at the surface of nano-crystallites. By trapping free electrons from the bulk, the hole accumulation layer region (HAL) with lower resistance is created, that lead to a current flow (illustrated by dark red arrows). HAL is illustrated by the blue transparent region, while core region is illustrated by dark yellow. (b) At exposure to hydrogen gas, the width of $\mathrm{HAL}$ region will decrease due to injected electrons from hydrogen gas molecules, which are oxidized to $\mathrm{H}_{2} \mathrm{O}$ molecules. As a result, the current flow through the HAL region will decrease, that is illustrated by smaller dark red arrows.

Thus, further investigations are needed to determine the acceptor centres origin related to zinc ion doping of the $\mathrm{Cu}_{2} \mathrm{O}$ and $\mathrm{CuO}$. Due to different oxidation states of copper ions in $\mathrm{Cu}_{2} \mathrm{O}\left(\mathrm{Cu}^{1+}\right)$ and $\mathrm{CuO}\left(\mathrm{Cu}^{2+}\right)$, incorporation of $\mathrm{Zn}^{2+}$ should occur by different mechanisms. In both cases, the concentration of holes is increased, which leads to a decrease of the electrical resistance value. ${ }^{13,81}$ Taking into account that the value of the sensor resistance under exposure to gas $R_{\text {gas }}$ can be theoretically very large, as a result sensor sensitivity $\left(S=R_{\text {gas }} / R_{\text {air }}\right)$ can be improved by decreasing the $R_{\text {air }}$ value. ${ }^{85}$ However, this can't explain the high selectivity to hydrogen gas of the Zn-doped copper oxide based sensors.

Since peaks of $\mathrm{ZnO}$ or $\mathrm{Zn}$ were not observed in the XRD data, it is reasonable to assume that most of $\mathrm{Zn}$ dopant is dispersed well on the surface of $\mathrm{CuO}$ nano-crystallites as amorphous $\mathrm{ZnO}{ }^{86}$ which was demonstrated by XPS measurements in previous work. ${ }^{81}$ Addition of $\mathrm{ZnO}$ to metal oxides is known to enhance the surface oxidation by $\mathrm{H}_{2}$ gas molecules, which lead to a higher selectivity to hydrogen gas. ${ }^{87} \mathrm{Yu}$ et al. ${ }^{87}$ demonstrated an increase in hydrogen gas selectivity by addition of $\mathrm{ZnO}$ to pellet-type $\mathrm{SnO}_{2}$ sensors. Also, the lower response of copper oxide based sensors more likely is induced by an inhibition of ethanol vapour molecules catalytic oxidation due to $\mathrm{Zn}$ doping of nano-material. ${ }^{13,16,20,86}$

\section{DFT calculations}

In order to gain further insights into the $\mathrm{H}_{2}$ sensing mechanism, we performed density functional theory based calculations on the interaction of $\mathrm{H}_{2}$ with $\mathrm{Zn}$-doped $\mathrm{CuO}(111)$ and $\mathrm{Cu}_{2} \mathrm{O}(111)$ surfaces.

Zn-Doped CuO surface. As already mentioned, we have used our earlier slab model for $\mathrm{CuO}(111)$, where at the base of the surface simulation cell two layers of atoms were fixed at their relaxed bulk positions to simulate the bulk phase of the crystal, while above these two layers, the surface was represented by two layers of atoms whose positions were allowed to change freely in the optimization process. The top layer consists of 3- and 4-coordinated $\mathrm{Cu}$ and $\mathrm{O}$ atoms. 3-Coordinated $\mathrm{O}$ atoms $\left(\mathrm{O}_{\mathrm{SuF}}\right)$ are the most exposed atoms, each connected to one 3-coordinated (coordinatively unsaturated - $\mathrm{Cu}_{\mathrm{CUS}}$ ) and two 4-coordinated (coordinatively saturated $-\mathrm{Cu}_{\mathrm{CSA}}$ ) $\mathrm{Cu}$ atoms (Fig. $\mathrm{S} 8 \dagger$ ). We first needed to identify the most energetically favourable dopant site for $\mathrm{Zn}$ ion on a $(1 \times 1)$ surface slab, which we achieved by substituting $\mathrm{Zn}$ in place of distinct surface $\mathrm{Cu}$ atoms in the top layer (Fig. S8 and $\mathrm{S} 9 \dagger$ ). We found that $\mathrm{Cu}_{\mathrm{CUS}}$ is the preferential site for $\mathrm{Zn}$ doping, as the $\mathrm{Cu}_{\mathrm{CUs}-\mathrm{Zn}}$ doped structure is more stable by $0.20 \mathrm{eV}$ compared to the $\mathrm{Cu}_{\mathrm{CSA}-\mathrm{Zn}}$ substituted structure. In order to comply with the experimental doping of $\sim 3 \%$, we next performed our calculations in a $(2 \times 1)$ supercell of $\mathrm{CuO}(111)$ surface (consisting of $31-\mathrm{Cu}, 32-\mathrm{O}$ and $1-\mathrm{Zn}$ atom), corresponding to $3.125 \%$ doping of $\mathrm{Zn}$. No reconstruction takes place as a result of $\mathrm{Zn}$ substitution and $\mathrm{Zn}$ binds to nearby surface oxygens, $\mathrm{O}_{\text {SUB }}$ and $\mathrm{O}_{\text {SUF }}$, with bond lengths of 1.928 and $1.855 \AA$ A respectively, as shown in Fig. S9. $\dagger$ As a result of doping, the band-gap decreases slightly by $\sim 0.1 \mathrm{eV}$, decreasing its value from $0.900 \mathrm{eV}$ in the undoped $\mathrm{CuO}(111)$ to $0.890 \mathrm{eV}$ in the Zn-doped $\mathrm{CuO}(111)$ surface.

Next, we modelled the interaction of the $\mathrm{H}_{2}$ molecule with this $\mathrm{Zn}$-doped $\mathrm{CuO}(111)$ surface. In a series of calculations, we first placed the $\mathrm{H}_{2}$ molecule close to all surface atoms in different orientations, but we found that the molecule desorbs from the surface in all the initial input configurations, except when it was placed near the most exposed $\mathrm{O}_{\mathrm{SUF}}$ atoms. We observed that the bonds between the surface oxygen $\mathrm{O}_{\text {SUF }}$ and the $\mathrm{Cu}_{\mathrm{CUS}}$ surface atoms are broken, with $\mathrm{O}_{\text {SUF }}$ connecting to the $\mathrm{H}_{2}$ molecule to form an adsorbed water molecule, as shown in Fig. 7. The same $\mathrm{O}_{\text {SUF }}$ is bonded to the $\mathrm{Zn}$ atom on the surface with a bond length of 2.022 A. Moreover, among all the surface $\mathrm{O}_{\text {SUF }}$ atoms, the most stable configuration was found by placing the $\mathrm{H}_{2}$ molecule near the $\mathrm{O}_{\text {SuF }}$ atom, which is bonded to the $\mathrm{Zn}$ dopant atom. Our results are similar to recent work on $\mathrm{H}_{2}$ adsorption on an undoped $\mathrm{CuO}(111)$ surface, ${ }^{88}$ where the bond between the surface oxygen $\mathrm{O}_{\mathrm{SuF}}$ to the $\mathrm{Cu}_{\mathrm{CSA}}$ atoms is broken and $\mathrm{O}_{\text {SuF }}$ connects to a nearby $\mathrm{Cu}_{\text {CUs }}$ surface copper atom after forming a $\mathrm{H}_{2} \mathrm{O}$ molecule. Our calculated binding energy is $-80.1 \mathrm{~kJ} \mathrm{~mol}^{-1}$, which is $\sim 8 \mathrm{~kJ} \mathrm{~mol}^{-1}$ larger than that achieved on the $\mathrm{CuO}(111)$ surface without $\mathrm{Zn}$-doping. The charge density difference, together with Bader charge analysis (Fig. 7), shows that there is significant charge transfer between the newly formed $\mathrm{H}_{2} \mathrm{O}$ molecule and surface atoms $\mathrm{Cu}_{\mathrm{CSA}}$ and $\mathrm{O}_{\text {SuF }}$. As a result of the $\mathrm{H}_{2}$ molecule interaction with the surface, the Fermi energy increases by $0.210 \mathrm{eV}$, from -1.563 to $-1.353 \mathrm{eV}$, while the calculated band-gap decreases by only $\sim 1.3 \%$ to $0.877 \mathrm{eV}$. The calculated densities of states are shown in Fig. S10a. $\dagger$

$\mathrm{Zn}$-Doped $\mathrm{Cu}_{2} \mathrm{O}$ surface. Here, we have again used our earlier slab model, consisting of five atomic layers, in which the three uppermost layers were free to relax during the optimization, while the bottom two layers were kept frozen at the optimised bulk positions. The $\mathrm{Cu}_{2} \mathrm{O}(111)$ surface consists of four different 
(a)
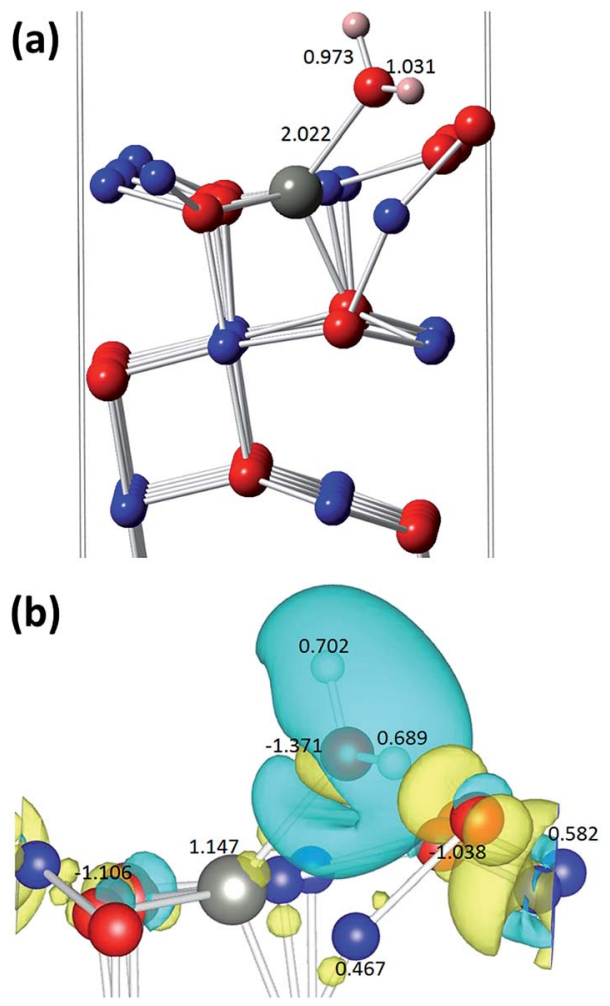

Fig. 7 (a) Side view of $\mathrm{H}_{2}$ on the $\mathrm{Zn}$-doped $(2 \times 1)$ slab of the $\mathrm{CuO}(111)$ surface, (b) electronic density difference plot of the $\mathrm{H}_{2}$ bonded structures on the $\mathrm{Zn}$-doped $\mathrm{CuO}(111)$ surface, showing charge transfer in the regions between the $\mathrm{H}_{2}$ and the surface atoms upon interaction. Blue contours indicate electron density increases by 0.01 electrons $\AA^{-3}$ and yellow contours indicate electron density decreases by 0.005 electrons $\AA^{-3}$. Bader charge values are in $\mathrm{e}^{-}$. $\mathrm{Cu}, \mathrm{O}, \mathrm{Zn}$ and $\mathrm{H}$ atoms are represented by blue, red, grey and salmon pink colours respectively.

atomic sites in the top layer, namely a coordinatively unsaturated copper $\mathrm{Cu}_{\mathrm{CUS}}$, an outermost oxygen $\mathrm{O}_{\mathrm{SUF}}$, a coordinatively saturated copper $\mathrm{Cu}_{\mathrm{CSA}}$ and a sub-surface oxygen atom $\mathrm{O}_{\mathrm{SUB}}$, which is 4-fold coordinated as shown in Fig. S11. $\dagger$ Similar to the $\mathrm{CuO}(111)$ surface, we have doped $\mathrm{Zn}$ into a $(2 \times 1)$ supercell slab (consisting of $40 \mathrm{Cu}$ and 200 atoms in five layer slab), corresponding to $2.5 \%$ doping (Fig. S12 $\dagger$ ). However, in order to maintain charge neutrality, as a result of substitution of $\mathrm{Zn}^{2+}$ ion in place of $\mathrm{Cu}^{1+}$ in $\mathrm{Cu}_{2} \mathrm{O}$, we also created a $\mathrm{Cu}$ vacancy by removing one $\mathrm{Cu}$ atom near the $\mathrm{Zn}$ dopant atom. We investigated two configurations by substituting two distinct surface coppers atoms, $\mathrm{Cu}_{\mathrm{CUS}}$ and $\mathrm{Cu}_{\mathrm{CSA}}$, and creating nearby $\mathrm{Cu}$ vacancies. We found that the $\mathrm{Cu}_{\mathrm{CSA}}$-substituted structure, shown in Fig. S12, $\dagger$ is $0.21 \mathrm{eV}$ more stable. As a result of the $\mathrm{Cu}$ vacancy, surface reconstruction takes place and in the relaxed surface structure, the bond is broken between the $\mathrm{Cu}_{\mathrm{CUs}}$ atom close to the vacancy and the oxygen atom in the second layer; the $\mathrm{Cu}_{\mathrm{CUS}}$ then bonds to one top surface oxygen atom, $\mathrm{O}_{\mathrm{SUF}}$, and one sublayer oxygen atom, $\mathrm{O}_{\mathrm{SUB}}$, with bond lengths of 1.827 and $1.886 \AA$, respectively. The $\mathrm{Zn}$ atom binds to $\mathrm{O}_{\text {SUF }}, \mathrm{O}_{\text {SUB }}$ and an oxygen atom in the second layer with bond lengths of $1.833 \AA$, $1.886 \AA$ and $2.016 \AA$, respectively. We have shown side and top views with annotated bond lengths in Fig. S12. $\dagger$ We note that with this $2.5 \%$ doping of $\mathrm{Zn}$, the bandgap of the slab does not change, remaining at $0.824 \mathrm{eV}$.

We next investigated the interaction of the $\mathrm{H}_{2}$ molecule with the surface and found that the $\mathrm{H}_{2}$ molecule dissociates on the surface with a small binding energy of $-24.6 \mathrm{~kJ} \mathrm{~mol}^{-1}$. This binding is weaker compared to that on the pristine $\mathrm{Cu}_{2} \mathrm{O}(111)$ surface without Zn-doping, ${ }^{\mathbf{4 2}}$ where the calculated binding energy for the dissociative adsorption of the $\mathrm{H}_{2}$ molecule was found to be $-78.6 \mathrm{~kJ} \mathrm{~mol}^{-1}$. As shown in Fig. 8, one of the $\mathrm{H}$ atom binds to the $\mathrm{Zn}$ atom with a bond length of $1.533 \AA$, while the other $\mathrm{H}$ atom binds to the nearby surface $\mathrm{O}_{\text {SUF }}$ atom with a short $0.978 \AA$ bond length. Bader charge analysis shows that one of the $\mathrm{H}$ atoms, bonded to $\mathrm{Zn}$, accepts a charge of $-0.309 \mathrm{e}^{-}$, while the second $\mathrm{H}$ atom, bonded to $\mathrm{O}_{\text {SuF }}$, transfers charge to the surface $\mathrm{O}_{\text {SUF }}$ atom, becoming $\mathrm{H}^{+}$with a calculated positive charge of 0.647 . As such, the hydrogen molecule has dissociated into a proton and hydride species, where one hydrogen atom transfers charge to a comparatively more electronegative surface oxygen atom, while the other hydrogen atom gains charge from a comparatively less electronegative surface $\mathrm{Zn}$ atom (Fig. 8). The Fermi energy of the system increases by $0.350 \mathrm{eV}$, from -1.274 to $-1.239 \mathrm{eV}$, while the calculated band gap decreases slightly by $\sim 5 \%$ as a result of the interaction of the $\mathrm{H}_{2}$ molecule with the surface, increasing to $0.865 \mathrm{eV}$ (Fig. S10†).

Our calculations reveal that the $\mathrm{Zn}$ doping influences the binding energies of the $\mathrm{H}_{2}$ molecule on both $\mathrm{CuO}$ and $\mathrm{Cu}_{2} \mathrm{O}$ surfaces and charge re-distribution takes place. While the Fermi

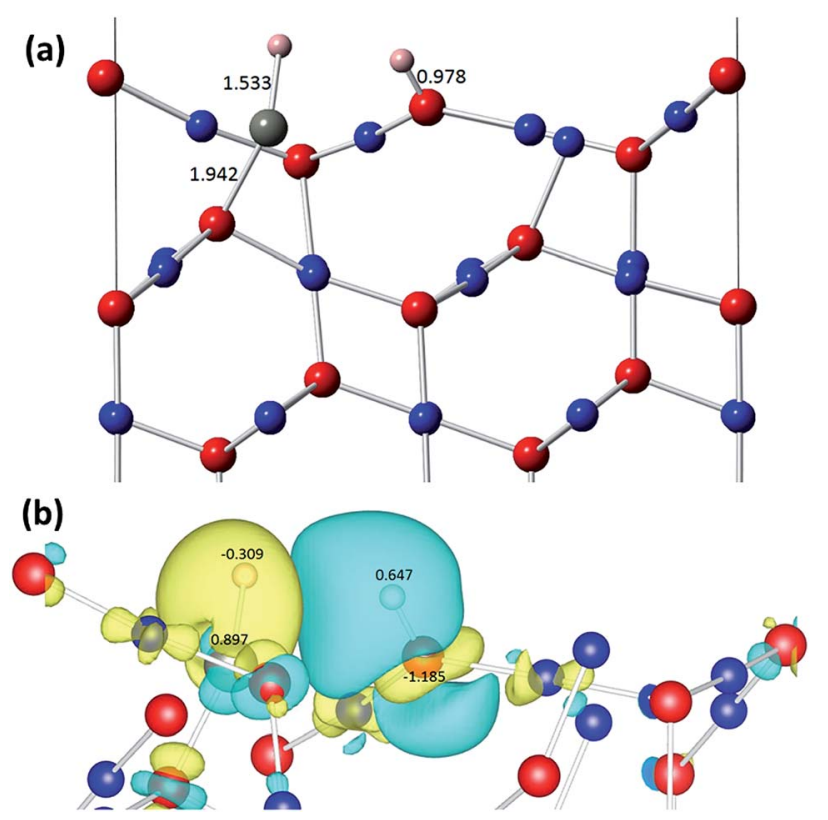

Fig. 8 (a) Side view of $\mathrm{H}_{2}$ on the $\mathrm{Zn}$-doped $(2 \times 1)$ slab of the $\mathrm{Cu}_{2} \mathrm{O}(111)-\mathrm{Cu}_{\text {vac }}$ surface, (b) electronic density difference plot of the $\mathrm{H}_{2}$ bonded structures on the $\mathrm{Zn}$-doped $\mathrm{Cu}_{2} \mathrm{O}(111)-\mathrm{Cu}_{\text {vac }}$ surface, showing charge transfer in the regions between the $\mathrm{H}$ atoms and the surface atoms upon interaction. Blue contours indicate electron density increases by 0.01 electrons $\AA^{-3}$ and yellow contours indicate electron density decreases by 0.003 electrons $\AA^{-3}$. Bader charge values are in $\mathrm{e}^{-}$. 
energy changes as a result of the interaction of the $\mathrm{H}_{2}$ molecule with the surface, the changes in the band-gaps are only small. Our results are similar to $\mathrm{H}_{2}$ sensing on $\mathrm{ZnO}$ surfaces, where the $\mathrm{H}_{2}$ molecule acts as a charge acceptor, decreasing the Fermi level by only a small change of $0.01 \mathrm{eV}$ in the band gap value. ${ }^{89}$

\section{Conclusions}

Structural, morphological, chemical and vibrational properties of as-grown and post-growth thermal treated copper oxide samples prepared via SCS were investigated in details. High crystallinity, mixed $\mathrm{Zn}$-doped $\mathrm{CuO} / \mathrm{Cu}_{2} \mathrm{O}$ phase and slight changes in the crystal constants of the samples have been demonstrated. XRD and micro-Raman studies of the as-grown $\mathrm{Cu}_{2} \mathrm{O}$ layers and of the RTA treated ones (RTA525 at $525{ }^{\circ} \mathrm{C}$ for $60 \mathrm{~s}$ ) detected two coexisting phases (cubic $\mathrm{Cu}_{2} \mathrm{O}$ and the monoclinic $\mathrm{CuO}$ ). The two phases ratio can be controlled by the Zn-doping level in SCS and by annealing regimes of TA or RTA.

Gas sensing investigations showed higher gas response and selectivity to hydrogen gas of the $\mathrm{Zn}_{x} \mathrm{Cu}_{1-x} \mathrm{O}_{y}$ nano-crystalline films with $3.0 \mathrm{wt} \% \mathrm{Zn}$ versus pure copper oxides. By $\mathrm{Zn}$ doping in copper oxide and formation of a nano-heterojunction after RTA at $525{ }^{\circ} \mathrm{C}$ for $60 \mathrm{~s}$ it was possible to change the sensing properties from ethanol vapour (pure copper oxide) to hydrogen gas (zinc-doped copper oxide with mixed phases). For samples RTA-treated at $525{ }^{\circ} \mathrm{C}$ for $60 \mathrm{~s}$ at operating temperature of $300^{\circ} \mathrm{C}$ the gas response for $100 \mathrm{ppm} \mathrm{H}_{2}$ was $S_{\mathrm{H}_{2}} \sim 765 \%$, which corresponds to an increase of sensor resistance by one order, with fast response times $\left(\tau_{\mathrm{r}} \sim 2.4 \mathrm{~s}\right)$ and recovery times $\left(\tau_{\mathrm{d}} \sim 6.9 \mathrm{~s}\right)$. Based on literature analysis, no reports on such high hydrogen gas response and selectivity of sensors based on p-type nanomaterials, have been published to-date by other groups. High crystallinity of the samples synthesized at relatively low temperatures $\left(\leq 80^{\circ} \mathrm{C}\right)$ and the existence of mixed $\mathrm{Zn}$-doped $\mathrm{CuO} / \mathrm{Cu}_{2} \mathrm{O}$ phases resulted in better sensing properties of the sensors and demonstrated good potential for fabrication of reliable, selective and fast hydrogen sensors with high gas response. A stabile sensor performances in humid air was found for $\mathrm{CuO}: \mathrm{Zn}$ by exposure of samples to rapid thermal annealing process for the first time.

Dispersion-corrected DFT $+U$ calculations were employed to investigate the hydrogen gas sensing mechanism on both the $\mathrm{CuO}$ and $\mathrm{Cu}_{2} \mathrm{O}$ surfaces, which revealed that $\mathrm{Zn}$ doping facilitates the binding of $\mathrm{H}_{2}$ where charge transfer between the molecule and the surface is responsible for the sensing behaviour.

Such nanomaterials are of great interest for other applications where a p-type oxide is requested.

\section{Acknowledgements}

Dr Lupan acknowledges the Alexander von Humboldt Foundation for the research fellowship for experienced researchers 3-3MOL/1148833 STP at the Institute for Materials Science, University of Kiel, Germany. This research was sponsored partially by the German Research Foundation (DFG) under the scheme AD 183/12-1. This research was partly supported by the
STCU within the Grant 5989. Professor Trofim Viorel (T.U.M.) is acknowledged for fruitful discussions and his support in the experimental part. AKM and NHdL acknowledge the Engineering and Physical Sciences Research Council (EPSRC) "4CU" programme grant (EP/K001329/1 and EP/K035355/1). NHdl also thanks the Royal Society for an Industry Fellowship.

\section{References}

1 Y. Xia, Z. Yang and Y. Zhu, J. Mater. Chem. A, 2013, 1, 93659381.

2 X. Xiao, C. Xu, J. Shao, L. Zhang, T. Qin, S. Li, H. Ge, Q. Wang and L. Chen, J. Mater. Chem. A, 2015, 3, 5517-5524.

3 R. Shabu, A. Moses Ezhil Raj, C. Sanjeeviraja and C. Ravidhas, Mater. Res. Bull., 2015, 68, 1-8.

4 L. Cheng, M. Shao, D. Chen and Y. Zhang, Mater. Res. Bull., 2010, 45, 235-239.

5 O. Lupan, G. A. Emelchenko, V. V. Ursaki, G. Chai, A. N. Redkin, A. N. Gruzintsev, I. M. Tiginyanu, L. Chow, L. K. Ono, B. Roldan Cuenya, H. Heinrich and E. E. Yakimov, Mater. Res. Bull., 2010, 45, 1026-1032.

6 D. P. Volanti, A. A. Felix, M. O. Orlandi, G. Whitfield, D.-J. Yang, E. Longo, H. L. Tuller and J. A. Varela, Adv. Funct. Mater., 2013, 23, 1759-1766.

7 O. Lupan, V. Cretu, V. Postica, M. Ahmadi, B. R. Cuenya, L. Chow, I. Tiginyanu, B. Viana, T. Pauporté and R. Adelung, Sens. Actuators, B, 2016, 223, 893-903.

8 O. Lupan, G. Chai and L. Chow, Microelectron. Eng., 2008, 85, 2220-2225.

9 H. J. Kang, P. Dai, B. J. Campbell, P. J. Chupas, S. Rosenkranz, P. L. Lee, Q. Huang, S. Li, S. Komiya and Y. Ando, Nat. Mater., 2007, 6, 224-229.

10 Y. Tokura, H. Takagi and S. Uchida, Nature, 1989, 337, 345347.

11 S. T. Shishiyanu, T. S. Shishiyanu and O. I. Lupan, Sens. Actuators, B, 2006, 113, 468-476.

12 I. M. Tiginyanu, O. Lupan, V. V. Ursaki, L. Chow and M. Enachi, in Compr. Semic. Sci. Tech., ed. P. B. F. Kamimura, Elsevier, Amsterdam, 2011, pp. 396-479, DOI: 10.1016/b978-0-44-453153-7.00105-x.

13 O. Lupan, V. Cretu, V. Postica, N. Ababii, O. Polonskyi, V. Kaidas, F. Schutt, Y. K. Mishra, E. Monaico, I. Tiginyanu, V. Sontea, T. Strunskus, F. Faupel and R. Adelung, Sens. Actuators, B, 2016, 224, 434-448.

14 Y.-H. Choi, D.-H. Kim, S.-H. Hong and K. S. Hong, Sens. Actuators, B, 2013, 178, 395-403.

15 N. G. Cho, I.-S. Hwang, H.-G. Kim, J.-H. Lee and I.-D. Kim, Sens. Actuators, B, 2011, 155, 366-371.

16 H.-J. Kim and J.-H. Lee, Sens. Actuators, B, 2014, 192, 607627.

17 L. Liao, Z. Zhang, B. Yan, Z. Zheng, Q. Bao, T. Wu, C. M. Li, Z. Shen, J. Zhang and H. Gong, Nanotechnology, 2009, 20, 085203.

18 T. B. Coplen, J. K. Böhlke, P. De Bievre, T. Ding, N. Holden, J. Hopple, H. Krouse, A. Lamberty, H. Peiser and K. Revesz, Pure Appl. Chem., 2002, 74, 1987-2017. 
19 J. Han, X. Zong, X. Zhou and C. Li, RSC Adv., 2015, 5, 1079010794.

20 A. S. Zoolfakar, M. Z. Ahmad, R. A. Rani, J. Z. Ou, S. Balendhran, S. Zhuiykov, K. Latham, W. Wlodarski and K. Kalantar-Zadeh, Sens. Actuators, B, 2013, 185, 620-627.

21 C. Yang, X. Su, F. Xiao, J. Jian and J. Wang, Sens. Actuators, B, 2011, 158, 299-303.

22 N. D. Hoa, S. Y. An, N. Q. Dung, N. Van Quy and D. Kim, Sens. Actuators, B, 2010, 146, 239-244.

23 N. D. Hoa, N. Van Quy, H. Jung, D. Kim, H. Kim and S.-K. Hong, Sens. Actuators, B, 2010, 146, 266-272.

24 O. Lupan, V. Postica, V. Cretu, N. Ababii, M. Hoppe, T. Pauporte, B. Viana, I. Tiginyanu and R. Adelung, Microelectron. Eng., 2016, under review.

25 O. Lupan, L. Chow, S. Shishiyanu, E. Monaico, T. Shishiyanu, V. Şontea, B. Roldan Cuenya, A. Naitabdi, S. Park and A. Schulte, Mater. Res. Bull., 2009, 44, 63-69.

26 O. Lupan, S. Shishiyanu, L. Chow and T. Shishiyanu, Thin Solid Films, 2008, 516, 3338-3345.

27 S. T. Shishiyanu, O. I. Lupan, E. V. Monaico, V. V. Ursaki, T. S. Shishiyanu and I. M. Tiginyanu, Thin Solid Films, 2005, 488, 15-19.

28 M. T. S. Nair, L. Guerrero, O. L. Arenas and P. K. Nair, Appl. Surf. Sci., 1999, 150, 143-151.

29 V. V. Ursaki, O. I. Lupan, L. Chow, I. M. Tiginyanu and V. V. Zalamai, Solid State Commun., 2007, 143, 437-441.

30 O. Lupan, L. Chow, T. Pauporté, L. Ono, B. R. Cuenya and G. Chai, Sens. Actuators, B, 2012, 173, 772-780.

31 O. Lupan, T. Pauporte, B. Viana, P. Aschehoug, M. Ahmadi, B. R. Cuenya, Y. Rudzevich, Y. Lin and L. Chow, Appl. Surf. Sci., 2013, 282, 782-788.

32 O. Lupan, T. Pauporté, I. Tiginyanu, V. Ursaki, V. Şontea, L. Ono, B. R. Cuenya and L. Chow, Thin Solid Films, 2011, 519, 7738-7749.

33 O. Lupan, V. Cretu, M. Deng, D. Gedamu, I. Paulowicz, S. r. Kaps, Y. K. Mishra, O. Polonskyi, C. Zamponi and L. Kienle, J. Phys. Chem. C, 2014, 118, 15068-15078.

34 G. Kresse and J. Hafner, Phys. Rev. B: Condens. Matter Mater. Phys., 1993, 47, 558-561.

35 G. Kresse and J. Hafner, Phys. Rev. B: Condens. Matter Mater. Phys., 1994, 49, 14251-14269.

36 G. Kresse and J. Furthmüller, Comput. Mater. Sci., 1996, 6, 15-50.

37 G. Kresse and J. Furthmüller, Phys. Rev. B: Condens. Matter Mater. Phys., 1996, 54, 11169-11186.

38 P. E. Blöchl, Phys. Rev. B: Condens. Matter Mater. Phys., 1994, 50, 17953-17979.

39 J. P. Perdew, K. Burke and M. Ernzerhof, Phys. Rev. Lett., 1996, 77, 3865-3868.

40 J. P. Perdew, K. Burke and M. Ernzerhof, Phys. Rev. Lett., 1997, 78, 1396.

41 S. L. Dudarev, G. A. Botton, S. Y. Savrasov, C. J. Humphreys and A. P. Sutton, Phys. Rev. B: Condens. Matter Mater. Phys., 1998, 57, 1505-1509.

42 A. K. Mishra, A. Roldan and N. H. de Leeuw, J. Phys. Chem. C, 2016, 120, 2198-2214.
43 M. K. Yaakob, N. H. Hussin, M. F. M. Taib, T. I. T. Kudin, O. H. Hassan, A. M. M. Ali and M. Z. A. Yahya, Integr. Ferroelectr., 2014, 155, 15-22.

44 A. K. Mishra, A. Roldan and N. H. de Leeuw, J. $\mathrm{CO}_{2}$ Util., 2016, DOI: 10.1016/j.jcou.2016.02.008.

45 S. Grimme, J. Comput. Chem., 2006, 27, 1787-1799.

46 H. J. Monkhorst and J. D. Pack, Phys. Rev. B: Condens. Matter Mater. Phys., 1976, 13, 5188-5192.

47 G. Henkelman, A. Arnaldsson and H. Jónsson, Comput. Mater. Sci., 2006, 36, 354-360.

48 Atoms in Molecules: A Quantum Theory, ed. R. F. W. Bader, Oxford University Press, London, 1994.

49 D. Chauhan, V. Satsangi, S. Dass and R. Shrivastav, Bull. Mater. Sci., 2006, 29, 709.

50 A. v. Richthofen, R. Domnick and R. Cremer, Fresenius' J. Anal. Chem., 1997, 358, 312-315.

51 A. Y. Oral, E. Menșur, M. H. Aslan and E. Bașaran, Mater. Chem. Phys., 2004, 83, 140-144.

52 T. H. Tran and V. T. Nguyen, Int. Scholarly Res. Not., 2014, 2014, 856592.

53 R. D. Shannon, Acta Crystallogr., Sect. A: Cryst. Phys., Diffr., Theor. Gen. Crystallogr., 1976, 32, 751-767.

54 O. Lupan, T. Pauporté, B. Viana and P. Aschehoug, Electrochim. Acta, 2011, 56, 10543-10549.

55 A. Li, H. Song, W. Wan, J. Zhou and X. Chen, Electrochim. Acta, 2014, 132, 42-48.

56 P. Chand, A. Gaur, A. Kumar and U. Kumar Gaur, Appl. Surf. Sci., 2014, 307, 280-286.

57 N. Mohamed Basith, J. Judith Vijaya, L. John Kennedy and M. Bououdina, Phys. E, 2013, 53, 193-199.

58 X-ray diffraction procedures, ed. H. P. Klug and L. E. Alexander, John Wiley \& Sons, inc., New York, 1954.

59 G. Williamson and W. Hall, Acta Metall., 1953, 1, 22-31.

60 S. Das and T. L. Alford, J. Appl. Phys., 2013, 113, 244905.

61 I. Singh and R. K. Bedi, Appl. Surf. Sci., 2011, 257, 7592-7599.

62 D. Prabhakaran and A. T. Boothroyd, J. Cryst. Growth, 2003, 250, 77-82.

63 R. Borzi, S. Stewart, G. Punte, R. Mercader, G. Curutchet, R. Zysler and M. Tovar, J. Appl. Phys., 2000, 87, 4870-4872.

64 T. V. Thi, A. K. Rai, J. Gim and J. Kim, Appl. Surf. Sci., 2014, 305, 617-625.

65 L. Armelao, D. Barreca, M. Bertapelle, G. Bottaro, C. Sada and E. Tondello, Thin Solid Films, 2003, 442, 48-52.

66 S. Asbrink and L. J. Norrby, Acta Crystallogr., Sect. B: Struct. Crystallogr. Cryst. Chem., 1970, 26, 8-15.

67 L. Debbichi, M. Marco de Lucas, J. Pierson and P. Kruger, J. Phys. Chem. C, 2012, 116, 10232-10237.

68 J. Chrzanowski and J. Irwin, Solid State Commun., 1989, 70, 11-14.

69 J. Xu, W. Ji, Z. Shen, W. Li, S. Tang, X. Ye, D. Jia and X. Xin, J. Raman Spectrosc., 1999, 30, 413-415.

70 M. H. Chou, S. B. Liu, C. Y. Huang, S. Y. Wu and C. L. Cheng, Appl. Surf. Sci., 2008, 254, 7539-7543.

71 H. Goldstein, D.-s. Kim, Y. Y. Peter, L. Bourne, J. Chaminade and L. Nganga, Phys. Rev. B: Condens. Matter Mater. Phys, 1990, 41, 7192. 
72 J. Irwin, J. Chrzanowski, T. Wei, D. Lockwood and A. Wold, Phys. C, 1990, 166, 456-464.

73 H.-L. Liu, C.-C. Chen, C.-T. Chia, C.-C. Yeh, C.-H. Chen, M.-Y. Yu, S. Keller and S. P. DenBaars, Chem. Phys. Lett., 2001, 345, 245-251.

74 H. Fan, B. Zou, Y. Liu and S. Xie, Nanotechnology, 2006, 17, 1099.

75 S. K. Maji, N. Mukherjee, A. Mondal, B. Adhikary and B. Karmakar, J. Solid State Chem., 2010, 183, 1900-1904.

76 K. Reimann and K. Syassen, Phys. Rev. B: Condens. Matter Mater. Phys., 1989, 39, 11113.

77 J. Chang, H. Kuo, I. Leu and M. Hon, Sens. Actuators, B, 2002, 84, 258-264.

78 N. Yamazoe, Sens. Actuators, B, 1991, 5, 7-19.

79 J. Fan and R. Freer, J. Appl. Phys., 1995, 77, 4795-4800.

80 M. Hübner, C. E. Simion, A. Tomescu-Stănoiu, S. Pokhrel, N. Bârsan and U. Weimar, Sens. Actuators, B, 2011, 153, 347-353.
81 O. Lupan, V. Cretu, V. Postica, O. Polonskyi, N. Ababii, F. Schutt, V. Kaidas, F. Faupel and R. Adelung, Sens. Actuators, B, 2016, 230, 832-843.

82 J. Ding, T. J. McAvoy, R. E. Cavicchi and S. Semancik, Sens. Actuators, B, 2001, 77, 597-613.

83 R. K. Bedi and I. Singh, ACS Appl. Mater. Interfaces, 2010, 2, 1361-1368.

84 A. Martínez-Ruiz, M. G. Moreno and N. Takeuchi, Solid State Sci., 2003, 5, 291-295.

85 C. W. Na, H.-S. Woo, I.-D. Kim and J.-H. Lee, Chem. Commun., 2011, 47, 5148-5150.

86 Z. Tianshu, P. Hing, Y. Li and Z. Jiancheng, Sens. Actuators, B, 1999, 60, 208-215.

87 J. H. Yu and G. M. Choi, Sens. Actuators, B, 2001, 75, 56-61. 88 Y. Maimaiti, M. Nolan and S. D. Elliott, Phys. Chem. Chem. Phys., 2014, 16, 3036-3046.

89 Q. Yuan, Y.-P. Zhao, L. Li and T. Wang, J. Phys. Chem. C, 2009, 113, 6107-6113. 